\title{
The importance of moral framing in pro-environmental behaviour - a field study
}

Supervised by Dr Adam Baimel

August 2019

A thesis submitted in part fulfilment of the regulations for the degree of Master of Science in Psychology, Oxford Brookes University 


\section{STATEMENT OF ORIGINALITY}

Except for those parts in which it is explicitly stated to the contrary, this thesis is my own work. It has not been submitted for any degree at this or any other academic or professional institution.

The copyright of this thesis rests with the author. Information derived from it should be acknowledged.

I agree that the thesis may be made available for reading and photocopying at the discretion of the Dean of the Faculty of Health and Life Sciences. Permission for anyone other than the author to reproduce or photocopy any part of the thesis must be obtained from the Dean of Faculty who will give his/her permission for such reproduction only to an extent which he/she considers to be fair and reasonable.

Signature

Date 


\section{CONTENTS}

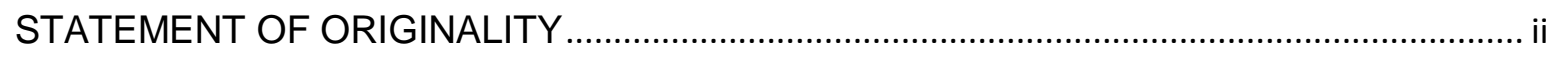

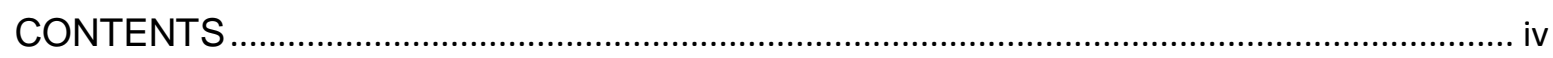

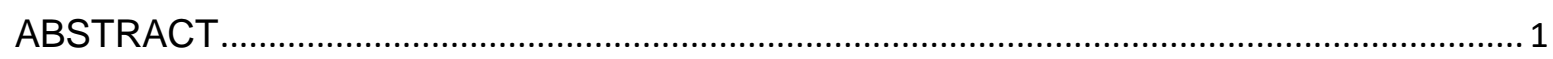

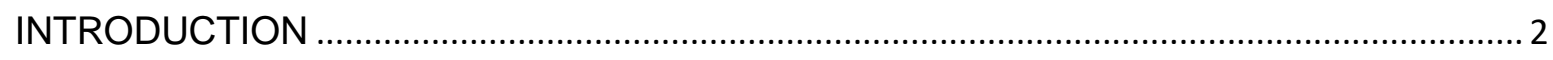

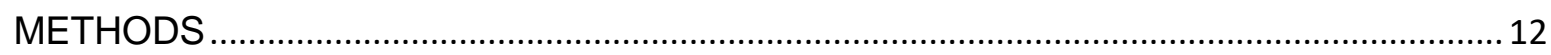

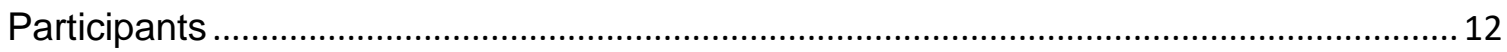

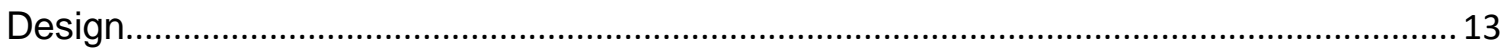

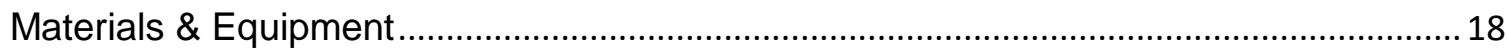

Procedure

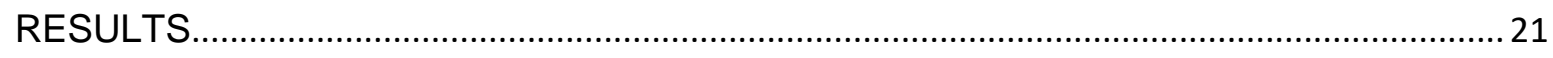

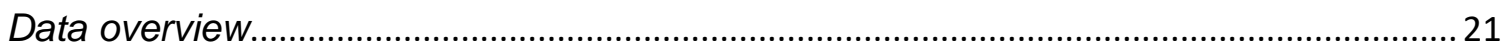

Research questions 1-3: Does the model predict behaviour in this case? ?....................... 25

Research question 4: Does self-control help explain pro-environmental behaviour?...... 34

Research question 5: What is the relative performance of the EAI vs. NEP? .................. 34

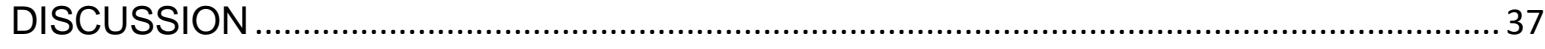

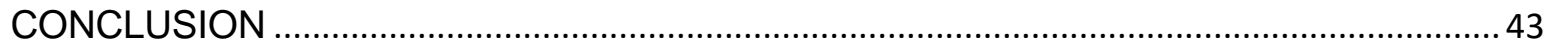

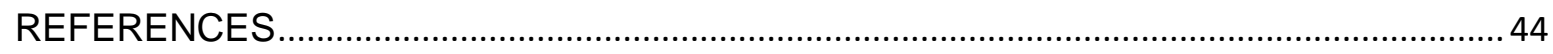

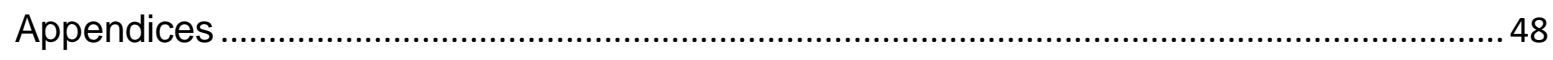

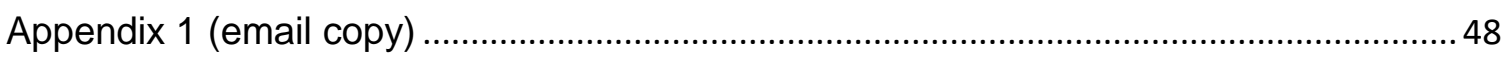

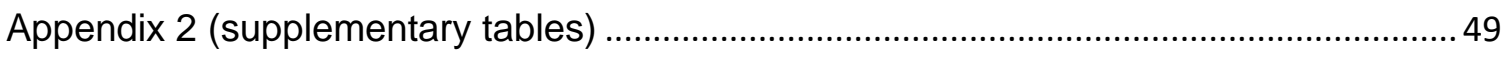

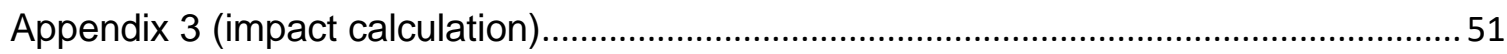

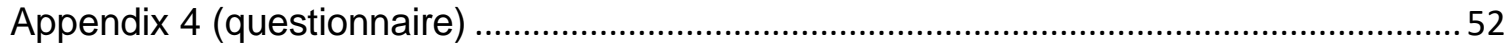




\section{ABSTRACT}

Pro-environmental behaviour (PEB) amongst the general public is recognised as an important part of solutions to long-term human sustainability, but describing and predicting it is complex and further experimental evidence is required to do so reliably. This research takes one model, the Comprehensive Action Determination Model (CADM), and tested it for predictive validity in a field experiment by linking covertly observed, anonymous data on domestic thermostat usage to values, attitudes, beliefs and behavioural intentions. An experimental manipulation was employed in order to demonstrate causality of predictor variables on behaviour.

The well established 'attitude-behaviour gap' is observed as expected, but results provide support for the CADM in terms of predicting actual behaviour. Within this, the moralising of an issue (or not) showed the greatest correlation with actual behaviour ie. those who regard thermostat setting as a moral issue are more likely to show the proenvironmental behaviour above all other predictor variables, including intention. The experimental manipulation did not show a significant effect, demonstrating the difficulties of producing real-world behaviour change. Other key findings suggest that, contrary to other studies, in this case self-control does not increase pro-environmental behaviour. In addition, despite criticism of the New Environmental Paradigm as a scale to measure general environmental attitudes this study shows that it performs very similarly to its main alternative, the Environmental Attitude Inventory. Implications and future research are considered, in particular the need to further understand the mechanisms by which certain issues become moralised whilst other do not. 


\section{INTRODUCTION}

Human impact on environmental systems is one of the major threats to humanity's existence (Centre for the Study of Existential Risk, 2019). The actions of private individuals are crucial in determining our collective response to these threats, both in terms of their direct and immediate contributions (e.g. reducing personal carbon footprint), and their influence on public policies (Stern, 2000b). Prior to the COVID-19 pandemic, in the UK issues of Brexit and Healthcare dominated public awareness, but concern for the environment was material and increasing. In longitudinal tracking, environmental concern was rated as the third most important issue facing the UK in December 2019, ahead of immigration, the economy and crime (YouGov, 2019). Human actions, however, all too often fail to follow from concern for an issue - known in the psychological sciences as the 'Attitude-Behaviour gap' (Kollmuss \& Agyeman, 2002). So even when concern is high, it remains a challenge for scientists to identify how that concern is translated into action.

This research uses a covertly observable, everyday pro-environmental behaviour (PEB), in the form of thermostat setting for domestic room heating. This data is compared it to an individual's stated environmental values, attitudes, beliefs and behavioural intentions. Does greater concern for the environment correlate with greater proenvironmental behaviour? What factors are important in increasing or decreasing that gap?

This dissertation first considers models of pro-environmental behaviour and what they might reveal about the gap between what people think or feel, and what they actually do. It will then go on to explain how one particular model's validity may be strengthened through behavioural research, considering issues of best practice in methodology and measurement. The review will also propose three specific areas where further research could improve its explanatory power; the role of moral values, choice of attitude scale, and the importance of self-control. 


\section{Models of pro-environmental behaviour}

At the broadest level, attitudes and behaviours may be viewed within an overall framework of moral values held by an individual. What do individuals think about particular issues? What is the right action to take in a given circumstance? Answers to these questions stem from moral values. Beliefs that some behaviours are moral obligations can be potent motivator, as shown by how 'sacred values' are central to taking severe actions like those involving risk of life (Atran, 2016). Such actions are extreme and not part of most people's everyday experience, but the extent of holding certain moral values has also been shown to correlate with PEB's. This has been found both in general terms and also in the specific examples of recycling, and electricity usage (Black et al., 1985; Karp, 1996; Stern \& Dietz, 1994; Thøgersen, 1996). The gap in translating such values into PEB's may indeed be owed to the fact that some issues, such as climate change, do not directly activate our moral reasoning (Markowitz \& Shariff, 2012). Research has shown that humans generally share a common set of moral concerns (Curry et al., 2019), but there are individual differences in how moral frames activate responses, for example between liberals and conservatives (Feinberg \& Willer, 2013). Therefore an important avenue for this research to examine is whether individuals who do act pro-environmentally do so as a result of their beliefs and attitudes being moralised and within that which moral frames are most effective.

In addition to moralising, many other factors predict the extent of a person's proenvironmental behaviour. Personal and social norms have been shown to mediate PEBs, as have attribution of causation, personal habits, costs as well as practical barriers such as the distance to recycling facilities (Bamberg \& Möser, 2007; Gifford, 2014; Klöckner, 2013). Hence, PEB's are not solely determined by a person's moral values and a variety of models have been proposed to synthesize a coherent picture of pro-environmental behaviour. 
Models of human behaviours tend to contain trade-offs between breadth and descriptive power for a specific behaviour (Gifford, 2014). Narrower models tend to predict PEB's more accurately from closely related variables, but miss the big picture and are therefore less generalisable. More comprehensive models, on the other hand, give a better overall sense of what influences behaviour, but are less powerful in predicting any specific PEB (Gifford, 2014). Thus the selection of a model for further research depends in large part on the purpose for which it is being used. In a review of empirical morality research it is suggested that it would be most helpful to study, where possible, a whole chain of events from antecedent values through to individual behaviours (Ellemers et al., 2019). In addition, more empirical research is required to ensure external validity of findings with regard to actual behaviour. Thus, the empirical study of a model which considers psychological variables from values through to behaviours presents an opportunity to build an informative picture of what drives PEB's.

One model of this type is Values-Beliefs-Norms (VBN). VBN is structured around the idea of a chain of events from values, through beliefs and attitudes to behaviour (Stern, 2000b). Core to the concept is the idea that PEB's can be predicted from a sequence of antecedent variables. It has been shown that the effect of personal habits is important when predicting PEB's (Carrington et al., 2012; Ouellette \& Wood, 1998) and VBN models do not include this element (Klöckner, 2013). VBN models do however provide a good basis for more empirically founded predictive models of PEBs.

Meta-analytic structural equation modelling has been used to develop more comprehensive models of PEB's (Bamberg \& Möser, 2007; Klöckner, 2013). Klöckner's "Comprehensive Action Determination Model" (CADM) covers the span of the psychological variables discussed in this review; moral values, attitudes and norms, and builds on the behavioural theories outlined above by including the effect of personal habit. The CADM, based on a data-set of 56 studies and shows a system of relationships involving eleven separate predictor variables, is shown in Figure 1. The model follows the 
path-like structure of VBN theory, starting with personal and broad environmental values on the left, feeding in to mediating variables such as Social Norms and Perceived Behavioural Control, which result in Intention and finally the behaviour itself.

FIGURE 1: KLÖCKNER'S 'COMPREHENSIVE ACTION DETERMINATION MODEL’ (CADM)

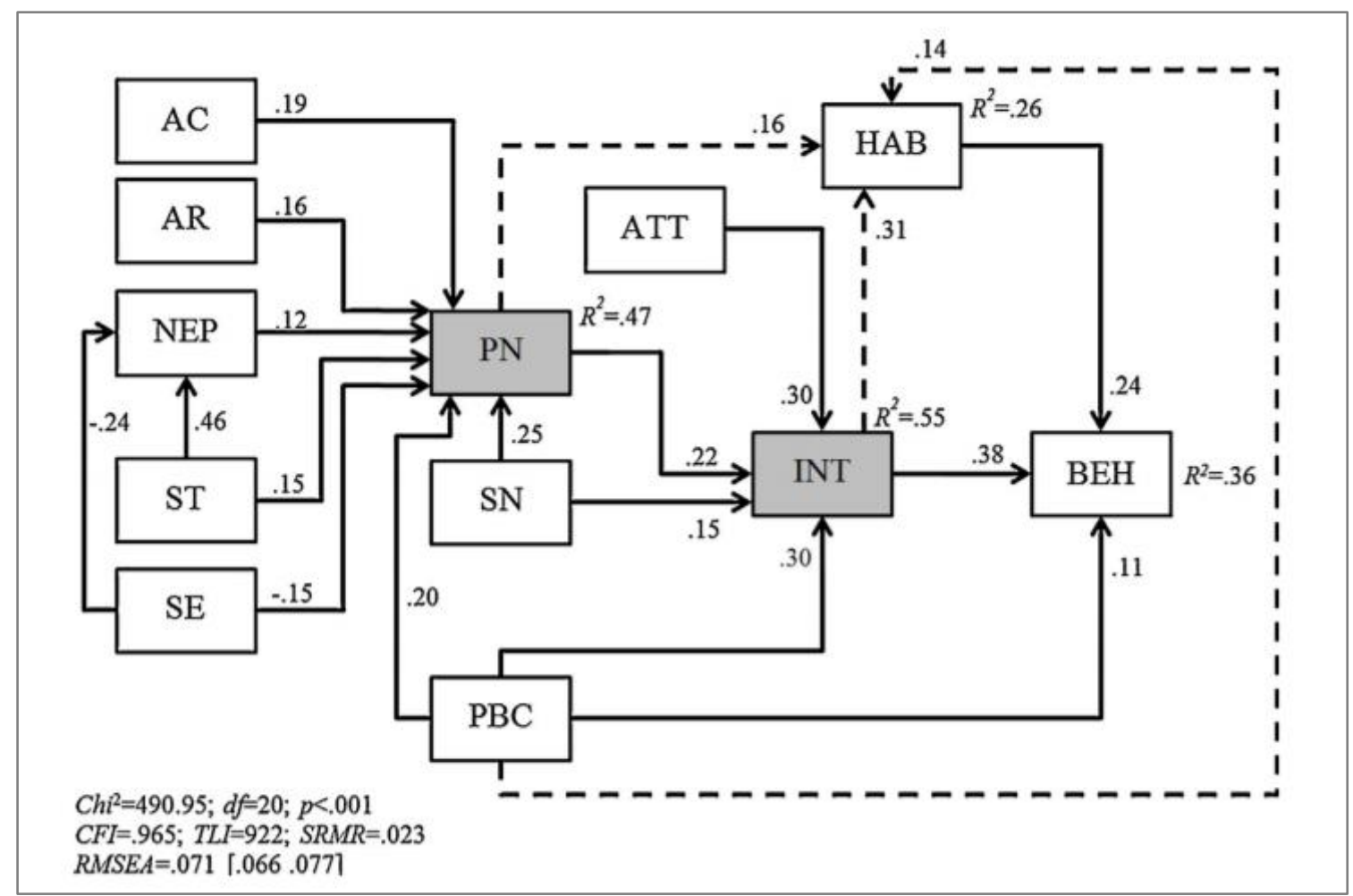

Note: AC, awareness of consequences; AR, ascription of responsibility; ATT, attitudes; BEH, behaviour; HAB, habit; INT, intention; NEP, new environmental paradigm; PBC, perceived behavioural control; PN, personal norm; SN, social norm; ST, self-transcendence values; SE, self-enhancement values.

This model is only just acceptable in terms of overall model-fit statistics (RMSEA $=$ 0.071), though this is unsurprising as it covers such a wide range of behaviours (including car buying, waste recycling and meat consumption for example). PEB's can be highly domain specific. For example, someone may be a vegetarian for reasons of health or cost rather than because of the environmental impact (Campbell-Arvai, 2015), or people who love the outdoors do not necessarily do so because they have pro-environmental attitudes (Thapa, 2010). As a result, in attempting a generalised model the explanatory power may be expected to be merely satisfactory, and will leave significant differences in behaviour unexplained (Gifford, 2014). The CADM incorporates a wide range of known relationships 
and thus offers the ability to examine end-to-end relationships driving PEB's. As such it is a desirable model for further study. There are however a number of important factors from previous studies to take into account when designing new research into environmental behaviours.

One important finding is that the effect of attitudes on behaviour has been shown to vary depending on the costs to the individual concerned. Costs can be financial, but can also be related to convenience or time required for a particular behaviour. Higher cost, inconvenient and/or time-consuming actions have been shown to be less influenced by attitudes. In these cases, situational factors take greater precedence (Diekmann \& Preisendörfer, 2003; Farjam et al., 2019). This is referred to as the 'low-cost hypothesis'. This effect has been shown in household energy consumption where PEB's were shown to be much more affected by attitudes for low-cost actions such as thermostat setting, than high-cost items such as adding insulation (Black et al., 1985). Thus, low-cost behaviours are preferred in studying PEB effects because they are more directly linked to the psychology of the action, rather than their required resources.

A further consideration with respect to the CADM is that researchers have consistently found that specificity matters in predicting pro-environmental behaviour. Generalised attitudes (e.g., "I care about the environment") do not consistently lead to specific behaviours (e.g., "I make sure that my thermostat is not set too high") hence contributing to the attitude-behaviour gap. Within the Theory of Planned Behaviour this has been termed 'compatibility' (Ajzen, 1988). For example, a study on organ donation showed that general attitudes to donation were poorer predictors of registration than specific attitudes reported to the act of registration itself (Siegel et al., 2014). Significant and meaningful correlations with behaviour have been shown when 'compatible' attitudes have been measured in examples on breast feeding, illegal drug use and physical exercise. This contrasts with non-significant or small effect sizes when behaviour is compared with generalised attitudes (Fishbein \& Ajzen, 2005). Such close correspondence has been 
criticised because asking for highly specific attitudes could be construed as a self-report of behaviour rather than an attitude (Kaiser et al., 2007). Future research should thus ensure that attitudes are measured in correspondence with behaviours whilst maintaining some differentiation.

Personality traits have also been shown to relate to prevalence of morality in decision making processes. Conscientiousness in particular is a predictor of moral identity and moral courage (Abbasi-asl \& Hashemi, 2019; Williams et al., 2006). A recent finding has shown that an individual's ability for self-control, measured by unhealthy food and alcohol habits, are associated with the Attitude-Behaviour gap with regard to environmentalism (Redondo \& Puelles, 2017). The latter is notable as self-control is not currently a variable included in the CADM and is thus recommended as an area for constructive study.

In summary, a key focus for psychologists is to understand and address the drivers of pro-environmental behaviour in order to advise on optimal policies and intervention strategies. A widely agreed, comprehensive and empirically validated psychological model of PEB's would be a valuable contribution to efforts to mitigate the threat posed by human impact on environmental systems. This research tests the CADM's predictive power by measuring a chain of variables from moral values, through attitudes and intentions to actual observed behaviour. Further areas for examination are the role of self-control and the relationship between behaviour and the extent to which PEB's are seen as fundamental moral obligations. This research focuses on a low-cost behaviour, and ensures that attitudes are measured at the correct level of specificity. In order to do this effectively it is important to consider how attitudes and behaviour are typically measured in this context. 


\section{Best practice in methodology and measurement}

When addressing the issue of measurement it is important to consider the type of behaviour and the optimal methodology for it. Three domains of Environmentally Significant Behaviour have been identified; Activism, Private, and Public sphere environmentalism (Stern, 2000b). 'Activism' is defined as a committed level of participation in demonstrations, environmental organisations and campaigning, although only a small proportion of people will take their pro-environmental behaviours this far. A large number will carry out less costly actions interacting either in the public sphere (e.g. signing a petition, support for an environmental charity or specific policy) or the private sphere (e.g. household recycling, energy or water use). The latter remain important because the large number of people involved can produce a large change in and of itself, but also because it can open up opportunities for wider change, like bolder pro-environmental policies from government. Conversely, behaviours themselves can retroactively influence attitudes (Olson \& Stone, 2005) and so have the potential to create a 'virtuous circle' of proenvironmental attitudes and behaviours.

How do researchers measure pro-environmental attitudes? The New Environmental Paradigm (NEP) is the most common measure of general environmental attitudes in the literature, correlates with other measures of environmental attitudes, and in some cases has been found to be predictive of behaviour (Dunlap, 2008). However, the NEP has been criticised for over emphasising certain types of environmental attitudes and for not keeping pace with contemporary views of environmentalism, in particular those invoking technological solutions (Hawcroft \& Milfont, 2010). A proposed improved scale of environmental attitude measurement is the Environmental Attitudes Inventory (EAI) (Milfont \& Duckitt, 2010). This scale may be psychometrically superior and more contemporary, but the NEP persists, probably due to its familiarity and the benefits of comparable historic data. The two scales have never been directly compared in a single study, so if possible this would be a useful addition to the literature. 
Measures of pro-environmental behaviours can take several forms; self-report, field observations and laboratory experiments (Lange \& Dewitte, 2019). Many experiments in environmental behaviour use self-report and in such cases validity has been shown to be inconsistent. For example in a study of recycling using direct observation, self-report was shown to have inconsistent relationships with actual behaviour depending on the type of recycling (Corral-Verdugo, 1997). A meta-study on PEB's found a correlation of $r=.45$ between self-report and actual behaviours (Kormos \& Gifford, 2014). Thus, self-report can be interpreted as a valid indicator of behaviour, whilst recognising that at this level of correlation it fails to explain $80 \%$ of the variation. Each method has strengths and weaknesses, but field experiments in this domain are most useful for their external validity (Lange \& Dewitte, 2019). It is recognised that the experimental method is the best method of assessing causal relationships. In addition, using established and validated measures of PEB's helps to enable progressive research. These factors have been included in the design of this research.

A final consideration with respect to measurement is that, as has been noted previously, external validity is an issue with morality research in general and specifically with regard to PEB's (Ellemers et al., 2019; Kormos \& Gifford, 2014). Values, attitudes, beliefs and intentions never fully explain behaviour. External context and cognitive bandwidth will influence whether a person will act pro-environmentally. In this case, the act of changing a thermostat setting requires the cognitive effort of awareness and attention as well as a little physical work. In addition, in this case of single occupancy rooms, the act is a private one, and thus not subject to the social norms or desirability effects which have been shown to influence environmental behaviour (Vesely \& Klöckner, 2018). As a result the real-world data available on thermostat usage is critical in providing veridical basis for evaluation of how these psychological variables affect behaviour in the real world. 


\section{Current research}

In summary, care for the environment is a major existential concern in which the behaviour of private individuals is a crucial factor. Understanding what drives those behaviours can make a useful contribution to setting policy and intervention strategies. From this review, there are five important questions which this research seeks to address. First, testing the validity of the CADM with a specific PEB which has low (non-financial) 'costs' and a concrete, observable behaviour and comparing that to values, attitudes, beliefs and behavioural intentions. Second, an experimental manipulation to demonstrate causality for the hypothesised chain of variables. Third, examining the extent to which moral concerns drive behaviour and whether the specific frame of that moral concern affects the outcome. Fourth, the Attitude-Behaviour gap has never fully been explained (Kollmuss \& Agyeman, 2002) and it is hypothesised that self-control may form part of what is missing from current explanations. Finally, the NEP and EAI scales had never been directly compared and therefore examining their relative predictive power for environmental attitudes and behaviours would be a valuable additional to the literature.

Thus, this dissertation asks the following research questions:

(1) Does measurement of thermostat usage, alongside self-reports of moral values and environmental attitudes, support the CADM? This will be evaluated by measuring the relationships between values, attitudes and the PEB from the new data in this study, and comparing those to the predicted correlations from the CADM. The statistical methods used will be simple bivariate correlations, linear regression and multi-level modeling using the time-series data. 
(2) Does an experimental intervention aimed at increasing the PEB do so in ways that are predicted by the model ie. do individual differences in key predictor variables such as Intention, Habit and Perceived Behavioural Control predict the magnitude of behaviour change? This will be measured by comparing the change in thermostat setting behaviour before and after the intervention to create a new dependent variable and repeating the analyses in (1).

(3) To what extent do broad moral values about the environment predict PEB's? This will be measured by correlation analyses of two moral values scales and their appearance as significant, or otherwise, in regression modelling. Further, can any differences in PEB be caused by using different moral frames? This is tested by splitting the experimental intervention into two test cells, each using a different communications frame, and comparing their effect.

(4) To what extent does self-control, as measured by the Brief Self-control Scale, help explain the PEB? Measured as in (3)

(5) What is the relative performance of the general environmental attitude scales, EAI and NEP, in predicting attitudes and the PEB? Measured as in (3) 


\section{METHODS}

\section{Participants}

Data was collected in two ways. Data recording the set point of the thermostat temperature control unit in student rooms is collected on an ongoing basis as part of Oxford Brookes environmental sustainability programme. This data was obtained for two separate halls of residence belonging to the University for the period of the study covering 552 student rooms in total. Individual consent was not required to analyse this data as it was not personally identifiable. Consent for use of the data was obtained from the University of Oxford Brookes. Therefore the inclusion criterion for this research was residence in either of these halls.

Additionally, an online questionnaire covering moral values, environmental attitudes and behavioural intentions was emailed to all residents of both halls, with a prizedraw incentive of a £25 Amazon voucher for each hall. Individual participants consented to use of their thermostat data as part of the questionnaire.

A total of eighty eight subjects completed the questionnaire, with a roughly even split from each hall of residence (Warneford, $n=45$; Crescent, $n=43$ ). Respondents were predominantly female (63\%), white $(72 \%)$ and had a mean age of $22(\mathrm{SD}=5.0,18-55$ years). A substantial minority (42\%) were born outside of the UK. Political orientation skewed towards liberalism, with a mean of $4.6(S D=1.35)$ on a 7-point Likert scale $(1=$ very conservative; 1 = very liberal) with only $22 \%$ of participants identifying on the conservative side of the spectrum. 


\section{Design}

The research had two main focus areas; first, the link between questionnaire responses and actual PEB as measured by the thermostat data and, second, the impact of an experimental manipulation designed to encourage hall residents to turn down their thermostats.

\section{Online questionnaire}

The online questionnaire covered the focal measures defined by the CADM are set out in Table 1. Questions were randomized within each question block.

TABLE 1: MAPPING VARIABLES TO THE CADM

\begin{tabular}{|c|c|c|}
\hline CADM variable & $\begin{array}{l}\text { Item, scale or } \\
\text { derived variable }\end{array}$ & Equivalent question or scale \\
\hline $\begin{array}{l}\text { Awareness of } \\
\text { consequences }(\mathrm{AC})\end{array}$ & Single item & $\begin{array}{l}\text { "I understand that my choices to lower or raise the setting of my } \\
\text { room thermostat has a direct impact on the environment." }\end{array}$ \\
\hline $\begin{array}{l}\text { Ascription of } \\
\text { responsibility (AR) }\end{array}$ & Single item & $\begin{array}{l}\text { "It is my responsibility to minimise my energy consumption by } \\
\text { adjusting my room's thermostatic control settings." }\end{array}$ \\
\hline NEP & Scale & NEP and EAI \\
\hline $\begin{array}{l}\text { Self-transcendence } \\
\text { values (ST) }\end{array}$ & Scale & Not measured. Morality scales used instead. \\
\hline $\begin{array}{l}\text { Self-enhancement } \\
\text { values (SE) }\end{array}$ & Scale & Not measured. Morality scales used instead. \\
\hline Social norm (SN) & Single item & $\begin{array}{l}\text { "It's a normal thing for people to do to adjust their thermostats, } \\
\text { in consideration of the impact on the environment." }\end{array}$ \\
\hline Personal norm (PN) & Derived variable & $\mathrm{N} / \mathrm{A}$ \\
\hline $\begin{array}{l}\text { Perceived behavioural } \\
\text { control (PBC) }\end{array}$ & Single item & $\begin{array}{l}\text { "I know that adjusting my thermostat setting will change the } \\
\text { amount of energy used to heat my room" }\end{array}$ \\
\hline Attitudes (ATT) & Scale & $\begin{array}{l}\text { Mean of } 3 \text { statements: } \\
\text { "I believe it is the morally right thing to do to use my thermostat } \\
\text { control to minimise energy usage" } \\
\text { "I feel bad when I think about having used energy } \\
\text { unnecessarily to heat my room" } \\
\text { "It would be wrong to use too much energy to heat my room } \\
\text { due to the negative consequences on the environment" }\end{array}$ \\
\hline Habits (HAB) & Single item & "I habitually adjust the thermostat setting in my room." \\
\hline Intentions (INT) & Single item & $\begin{array}{l}\text { "I fully intend to use my thermostat control to minimise energy } \\
\text { usage in the future" }\end{array}$ \\
\hline Behaviour (BEH) & - & $\begin{array}{l}\text { Measured through either; } \\
\text { 1. Likely pro-environmental behaviour self-report } \\
\text { (questionnaire) } \\
\text { 2. Observed thermostat data }\end{array}$ \\
\hline
\end{tabular}

Other scales used in the analysis were the Brief Self-Control Scale (BSCS)

(Lindner et al., 2015) to measure self-control, two scales measuring broad moral values in line with Moral Foundations Theory (MFT; Graham et al., 2011) and Morality as Co- 
operation (MAC; Curry et al., 2019), the Environmental Concerns and Actions scale measuring behavioural intentions (Bain et al., 2016), and the Environmental Attitudes Inventory-24 for comparison to the New Ecological Paradigm (NEP; Milfont \& Duckitt, 2010).

\section{Thermostat data}

Thermostat set-point readings from each room are recorded every 4 minutes but for manageability of the analysis, readings were averaged across one hour time segments. Only student rooms were included in the analysis. Average hourly thermostat reads for 2 weeks prior to the experimental intervention and 2 weeks post provided 708,622 observations across 552 rooms. The thermostat set point served as the focal measure of pro-environmental behaviour for this study.

Thermostat setting is regulated by a system of defaults (Table 2). These defaults limit the amount of control the room occupant has in order to minimize energy use and costs.

TABLE 2: CENTRALISED THERMOSTAT DEFAULT PROGRAMME

\begin{tabular}{|l|l|}
\hline 00:00 to 07:00 hours & $\begin{array}{l}\text { Default temperature } 19^{\circ} \mathrm{C} \text {. Any temperature override will stay in } \\
\text { effect until } 7 \text { am. The maximum temperature allowed overnight is } \\
21^{\circ} \mathrm{C}\end{array}$ \\
\hline 07:00 to $10: 00$ hours & $\begin{array}{l}\text { Default temperature of } 21^{\circ} \mathrm{C} \text { in the morning. Temperatures selected } \\
\text { above this will last for } 1 \text { hour. }\end{array}$ \\
\hline 10:00 to 16:00 hours & $\begin{array}{l}\text { Default temperature } 19^{\circ} \mathrm{C} \text { - any increases in temperature will time- } \\
\text { out after } 1 \text { hour. }\end{array}$ \\
\hline 16:00 to 00:00 hours & $\begin{array}{l}\text { Default temperature } 19^{\circ} \mathrm{C} \text { - any increases in temperature will time- } \\
\text { out after } 3 \text { hours. }\end{array}$ \\
\hline $\begin{array}{l}\text { For all cases at any time of the day a manual decrease in temperature beneath the default will } \\
\text { be permanent until the user overrides it - this change has been implemented to help students } \\
\text { that have reported as being too warm. } \\
\text { (taken from https://www.brookes.ac.uk/sustainability/heating/) }\end{array}$
\end{tabular}

The fieldwork was conducted in February to capitalise on the fact that external temperatures were low and room heating would be required. External ambient temperature was controlled for in focal analyses. Daily mean external temperature data for Oxford was obtained from Weather Online, a third-party source (https://www.weatheronline.co.uk/)). 
The focal measure of pro-environmental behaviour in this study was taken to be the mean thermostat set point over time. Responses to the questionnaire on moral attitudes towards thermostat setting (shown in Table 1 'Attitudes', p13) demonstrate that it is recognised as an environmental issue. These statements, showing agreement with the idea that thermostat setting as an environmental behaviour, were measured on a 7-point Likert scale of Agree/Disagree with zero as the mid-point. Responses showed $92 \%$ of participants agreed to some extent with at least two out the three statements, and $48 \%$ agreed with all three. Only $2 \%$ of participants disagreed with all three statements. This demonstrates that most people understood that thermostat setting is an environmental issue.

Upon inspection, the thermostat data was found to contain a number of large peaks (Figure 2) which do not correspond to the recorded room temperature data. This suggested that a measurement error may have been present. On investigation the peaks were seen to affect multiple rooms at identical times and that these times correlated with a lack of raw data readings during the time periods concerned. As a result 6 (of 696 ) data points were removed from the time period of analysis $\left(1^{\text {st }} \mathrm{Feb}-29^{\text {th }} \mathrm{Feb}\right)$ to ensure these outliers did not skew results. 


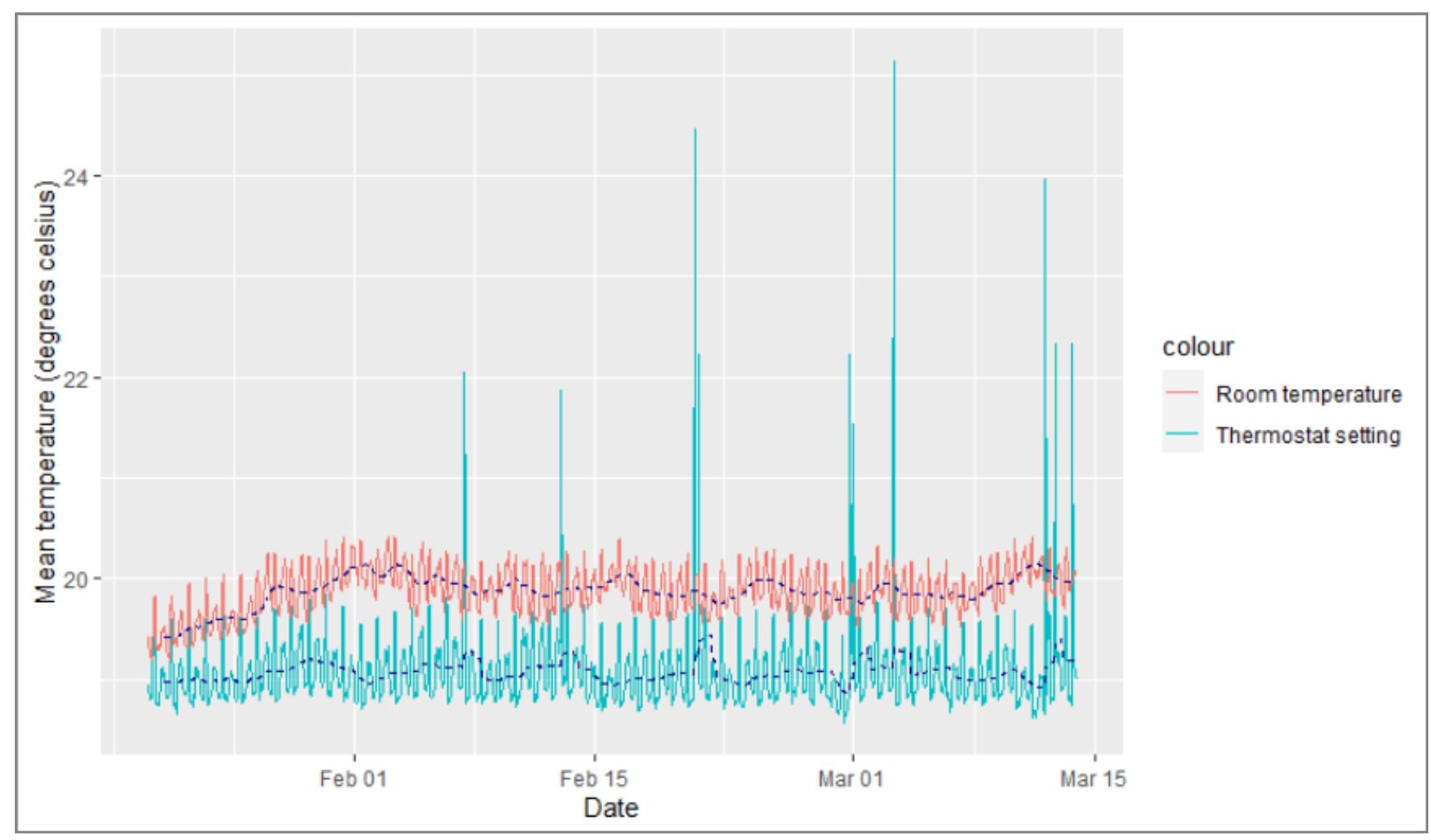

Overall, thermostat data was strongly influenced by the defaults imposed by the centralised thermostat control program. This program resets the thermostat back to either $19^{\circ} \mathrm{C}$ or $21^{\circ} \mathrm{C}$ as per the rules laid out in Table 2 . An example of the impact of this on the readings for a single room is presented in Figure 3 with the thermostat setting by design being heavily biased towards the default settings. This preset programming resulted in $73 \%$ of time-series observations within the analysis at programmed defaults (with $65 \%$ at $\left.19^{\circ} \mathrm{C}\right)$. Thus the data was analyzed in two ways. The first examined all the data. The second excluded the default settings and provides an additional measurement of behaviour that is more directly connected to intentional manipulation of the thermostat on behalf of the participant. The relative merits of these measurements are considered in the discussion. 
FIGURE 3: EXAMPLE SHOWING PREVALENCE OF DEFAULT THERMOSTAT SET-POINTS AT 19 AND 21 DEGREES

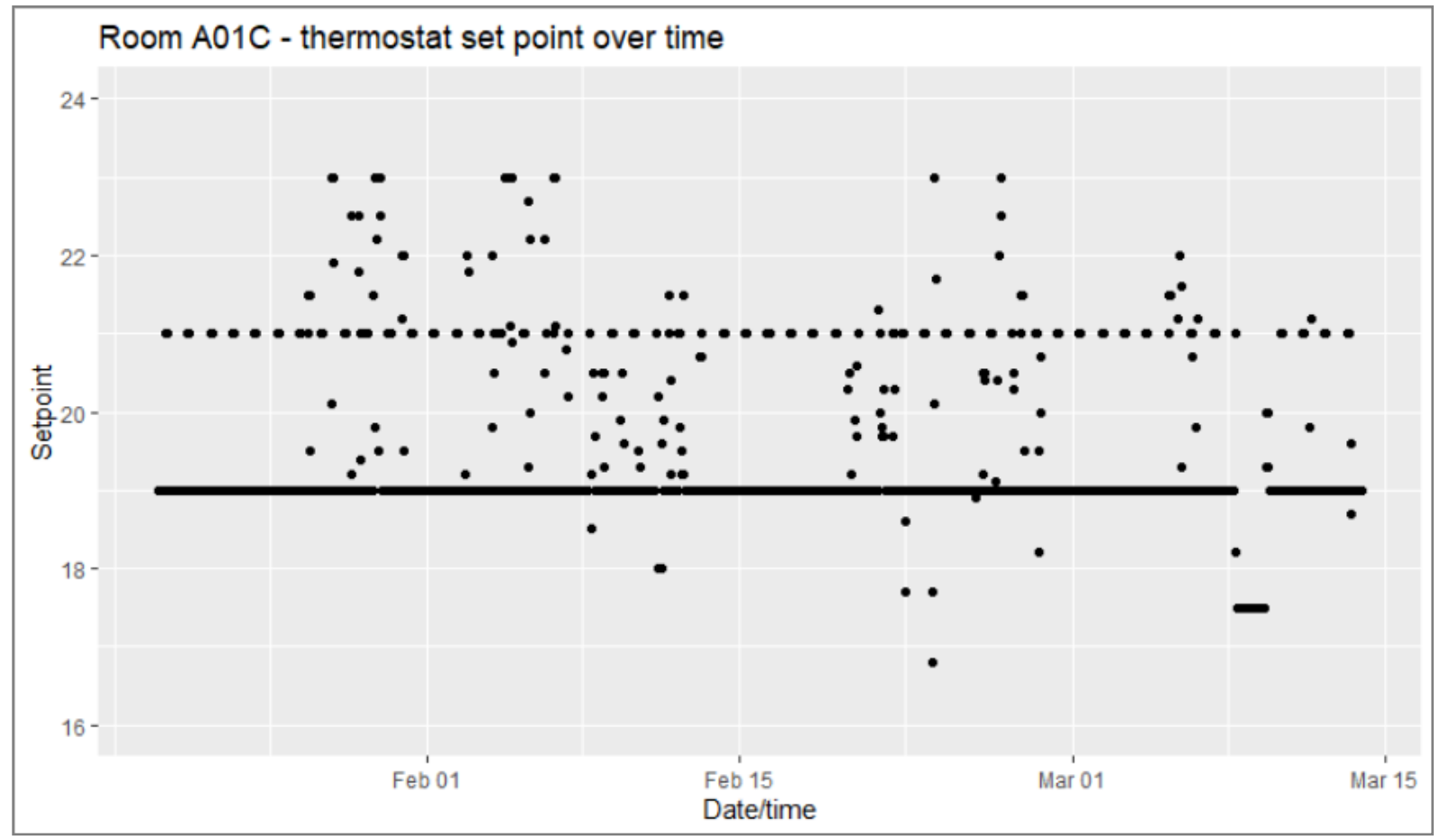

In addition to overall mean thermostat setting as a PEB, setting the thermostat lower as a result of the experimental manipulation was analysed as a pro-environmental behaviour.

Thus, four dependent variables were analysed;

I. Mean thermostat setting

II. Mean thermostat setting exc. defaults

III. Change in thermostat setting post experimental manipulation

IV. Change in thermostat setting post experimental manipulation exc. defaults 


\section{Materials \& Equipment}

A communication campaign was designed to elicit a response of lower thermostat setting a pro-environmental behaviour. Any variables which correlated with the PEB as a direct result of the experimental intervention would thus be shown to be causal. The experiment was conducted shortly after the Australian bush fires which ran from September 2019 until February 2020 and had received extensive media coverage, including their relationship to climate change (BBC News, 2020), so this was chosen as the theme of the campaign. The basic message was the same in both conditions, highlighting this topical issue and directly encouraging the lowering of room thermostats in response (Figure 4).

The two halls of residence were treated as separate conditions for the test of two moral frames, each receiving a variant of the communications campaign (Figure 4). One hall (Warneford) received a 'generic' framing, and in the other the copy was changed to reflect a 'family' moral frame. This was to test whether this specific moral frame from Morality As Co-operation would elicit a greater pro-environmental response. Of the seven types of morality as co-operation (Curry et al., 2019) 'family' was selected due to its potential relevance to future sustainability from the perspective of young adults.

FIGURE 4: THE COMMUNICATIONS CAMPAIGN - GENERIC \& 'FAMILY' FRAMES

OUR PLANET
IS BURNME

The terrible damage from recent Australian bush fires is a direct impact of climate change

Turning down your thermostat by just 1 degree can save up to $10 \%$

Set your thermostat to 18

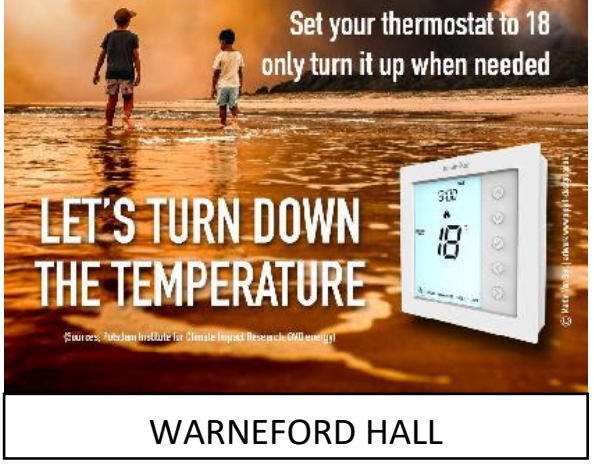

OOR PANT is BURWIT

The terrible damage from recent Australian bush fires is a direct impact of climate change Turning down your thermostat by just 1 degree can save up to $10 \%$

Set your thermostat to 18 only turn it up when needed

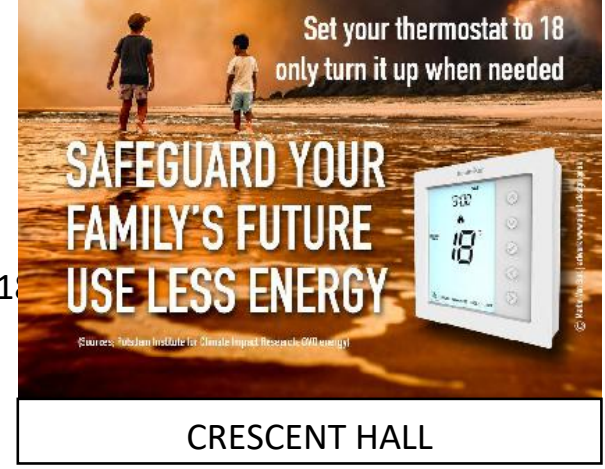


The communications campaign commenced on $14^{\text {th }}$ February 2020 , four days after the email questionnaires were sent. A copy of the email can be seen in Appendix 1 (email copy). Eighty six of the eighty eight survey responses were completed before the communications campaign began.

\section{Procedure}

The research study was approved by the Psychology Research and Ethics Committee at Oxford Brookes University, prior to data collection. An outline of the research questions, sampling plan including sample size rationale and key variables were preregistered within the Open Science Framework (https://osf.io/85wa6/).

To detect a correlation of .30 or higher, a minimum sample size of 84 was required (Bujang \& Baharum, 2016). The aim was for a higher sample size of 120 to give the study greater statistical power. To detect a difference between the two communications conditions 2 independent samples an effect size of 1 degree (5\%) change in thermostat setting at a power of $80 \%$ would require a sample of 282 participants (calculations used https://clincalc.com/stats/samplesize.aspx). With access to the data from 552 rooms, this was achievable for this study. The relative predictive power of NEP and EAI potentially required a much bigger sample size depending on the effect size. The CADM research shows that relationships between NEP and other variables in the model range from -.01 (self-enhancement values), to .45 (ascription of responsibility). To detect a difference from .3 to .4 would require a sample size of 605 (Bujang \& Baharum, 2016), which is beyond what was possible for this study. Thus, it was not expected that NEP/EAI would show large differences in their correlations as they are similar and designed to measure the same attitudes. However, the aim was to maximise sample size conduct the analysis to see if an effect could be detected. 
The online questionnaire was administered using Qualtrics software. Consent was recorded at the start of the questionnaire and included consent to link questionnaire responses to thermostat data. Each participant was required to select their hall and room number in order to facilitate linking of the two data sources. One room number was found to be duplicated and the survey data was not used in this case.

The experimental manipulation consisted of placing A3 posters in all communal areas e.g. kitchens and stairwells by hall staff and student wardens on official university noticeboards. In addition A5 leaflets of the same design were placed under every door. A visual inspection was carried out on $24^{\text {th }}$ February (10 days after posting) and $100 \%$ of posters were still in place. A precise time of day for the start of the campaign could not be specified. Thus, observations from $14^{\text {th }}$ February were analyzed as occurring before the manipulation.

Average hourly thermostat data was provided by University of Oxford Brookes sustainability team. For analysis, settings across 4 weeks ( 2 weeks before manipulation, 2 weeks after) were used. Term dates were enrolment from $20^{\text {th }}$ January with teaching commencing $27^{\text {th }}$ January, so all students would have been occupying rooms by the start of the measurement period and thermostat usage reached typical term-time levels by $26^{\text {th }}$ January.

It is worth noting that the impact of COVID-19 had not fully unfolded during the time period of observations, with the University operating as normal (albeit with some restrictions on travel with respect to China and Northern Italy) until face-to-face teaching was suspended on $17^{\text {th }}$ March; well after data collection was completed.

Data was analysed using $R$ in $R$ Studio. Both code and anonymised data will ultimately be made available as part of the Open Science Framework project (https://osf.io/jqdk4/). 


\section{RESULTS}

\section{Data overview}

Each of the scales employed were subjected to an exploratory factor analysis to examine potential underlying factor structures using parallel analysis and visual inspection of scree plots. The moral attitudes scale (specific to thermostat settings) was unifactorial, as were the scales of morality as co-operation (MAC), moral foundations theory (MFT), and brief self-control (BSCS). However, variance in the responses to the behavioural intentions scale was better explained by two factors. These two factors captured different domains of environmental action characterised as activist/political (e.g. vote for green candidates, join protests) and pragmatist/consumer (e.g. reduce car travel, recycle) (Table $3)$. 


\begin{tabular}{|c|c|c|}
\hline & $\begin{array}{c}\text { Factor } \\
1\end{array}$ & $\begin{array}{c}\text { Factor } \\
2\end{array}$ \\
\hline Sign a petition in support of protecting the environment & 0.25 & 0.35 \\
\hline Join or renew membership of an environmental group & 0.73 & -0.03 \\
\hline Join public demonstrations or protests supporting environmental protection & 0.67 & 0.05 \\
\hline $\begin{array}{l}\text { Write a letter or call your member of parliament or another government } \\
\text { official to support environmental protection }\end{array}$ & 0.83 & -0.09 \\
\hline Give money to an environmental group & 0.53 & 0.14 \\
\hline $\begin{array}{l}\text { Read a newsletter, magazine or other publication written by an } \\
\text { environmental group }\end{array}$ & 0.55 & 0.19 \\
\hline $\begin{array}{l}\text { If a local or national election was called, vote for a candidate in part because } \\
\text { he or she was in favour of strong environmental protection* }\end{array}$ & 0.25 & 0.28 \\
\hline e environment & 0.80 & -0.11 \\
\hline Boyc & 0.45 & 0.26 \\
\hline Volur & 0.65 & 0.25 \\
\hline $\begin{array}{l}\text { Post pro-environmental messages or links on social media (for example, } \\
\text { Facebook, Twitter) }\end{array}$ & 0.66 & 0.04 \\
\hline ally friendly products & 0.10 & 0.74 \\
\hline when cooking or showering) & -0.05 & 0.56 \\
\hline Minim & 0.17 & 0.57 \\
\hline Reduce car travel (for example, walk, cycle, use public transport) & -0.09 & 0.63 \\
\hline pliances when not in use & -0.02 & 0.63 \\
\hline reduce eating meat & 0.20 & 0.35 \\
\hline Recycle & -0.20 & 0.69 \\
\hline se 'standby' mode & 0.06 & 0.44 \\
\hline Eat fc & 0.13 & 0.56 \\
\hline Use & 0.19 & 0.33 \\
\hline Buy products with less packaging & 0.00 & 0.79 \\
\hline
\end{tabular}

Note: Fixed 2 factor solution using OLS minimum residuals and 'oblimin' rotation. *This item did not load strongly onto either factor and was therefore dropped from further analyses.

Two new (unweighted) variables were calculated to represent these factors representing different types of pro-environmental behaviour and each was shown to be internally consistent (Table 4). These two scales were correlated $(r=.50[.32 .64], t(86)=$ $5.30, p<.001)$. Other focal measures were checked for unifactorial internal consistency and all had satisfactory or good reliability as indexed by Cronbach's alpha (Table 4). 
TABLE 4: DESCRIPTIVE STATISTICS OF QUESTIONNAIRE DATA

\begin{tabular}{lccccc}
\hline & Scale range & Mean & SD & $\begin{array}{c}\text { Cronbach } \\
\text { Alpha }\end{array}$ & $\begin{array}{c}\text { Shapiro- } \\
\text { Wilk } \\
\text { p-value }\end{array}$ \\
\hline NEP & -3 to +3 & 1.2 & 0.67 & .74 & .23 \\
EAl-24 & -3 to +3 & 1.1 & 0.64 & .82 & .39 \\
BSCS & $1-5$ & 3.0 & 0.68 & .84 & .42 \\
Moral attitude & -3 to +3 & 1.2 & 0.95 & .82 & .08 \\
Claimed pro-environmental & $1-7$ & 5.0 & 0.95 & .90 & .38 \\
behaviours $^{\dagger}$ & $1-7$ & 4.0 & 1.40 & .88 & .06 \\
Eco-activist $^{\dagger}$ & $1-7$ & 5.7 & 0.90 & .83 & $.01^{*}$ \\
\hline Eco-pragmatist & & & & &
\end{tabular}

Note: Means, standard deviation and Alpha (raw scores) of key scales used in the study.

${ }^{\dagger}$ Scales derived from factor analysis of behavioural intentions scale.

Distribution of responses for all focal measures were normally distributed (as examined with QQ plots and the Shapiro-Wilk test), except for the 'Eco-pragmatist' scale although the plot reveals no particular issues with the distribution (Figure 6).

FIGURE 5: DISTRIBUTION OF RESPONSES TO QUESTIONS IN "PRAGMATIST" BEHAVIOUAL INTENTIONS SCALE

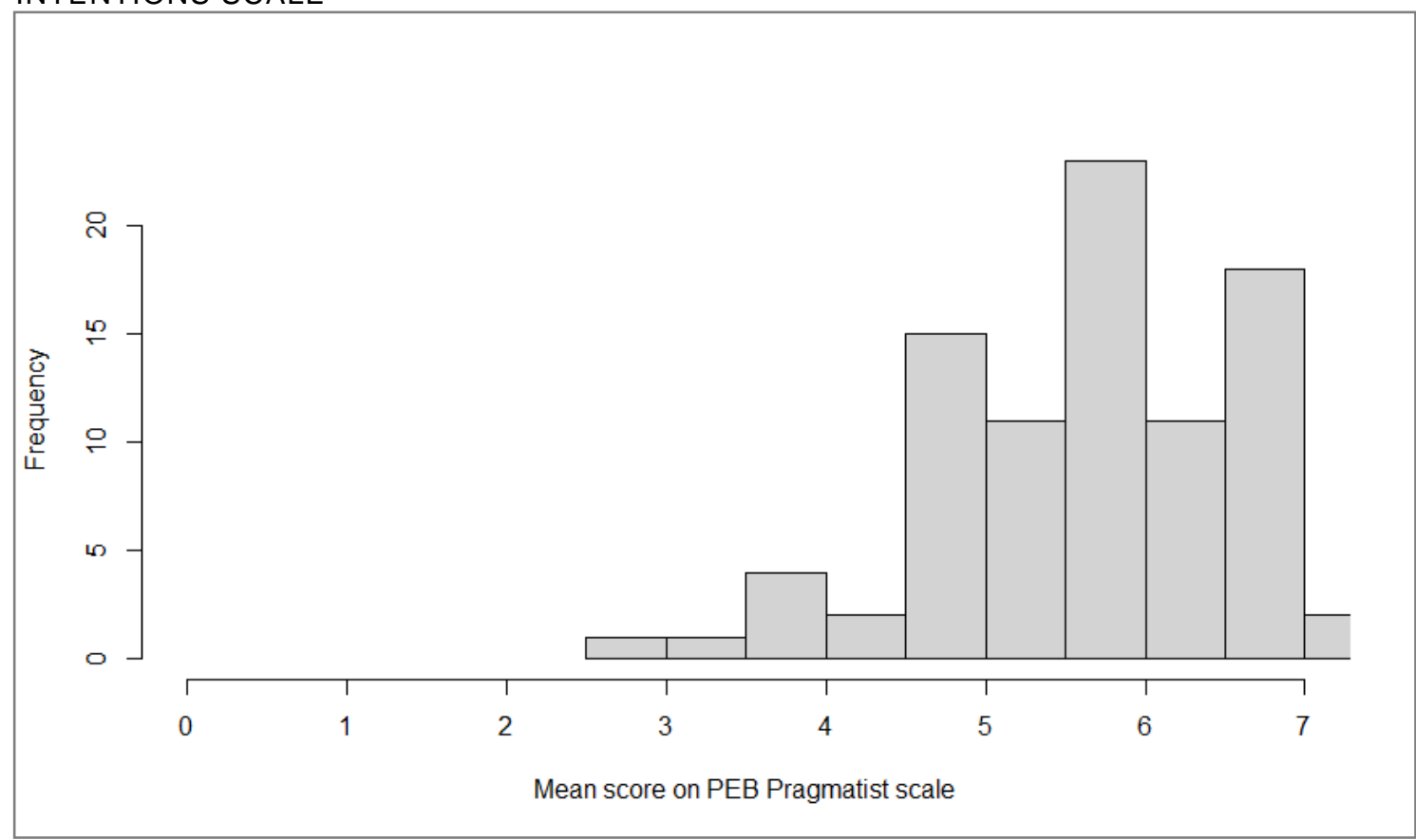


External temperature and thermostat settings are shown in Figure 7.

FIGURE 6: THERMOSTAT AVERAGE SETPOINT VARIATION WITH EXTERNAL TEMPERATURE

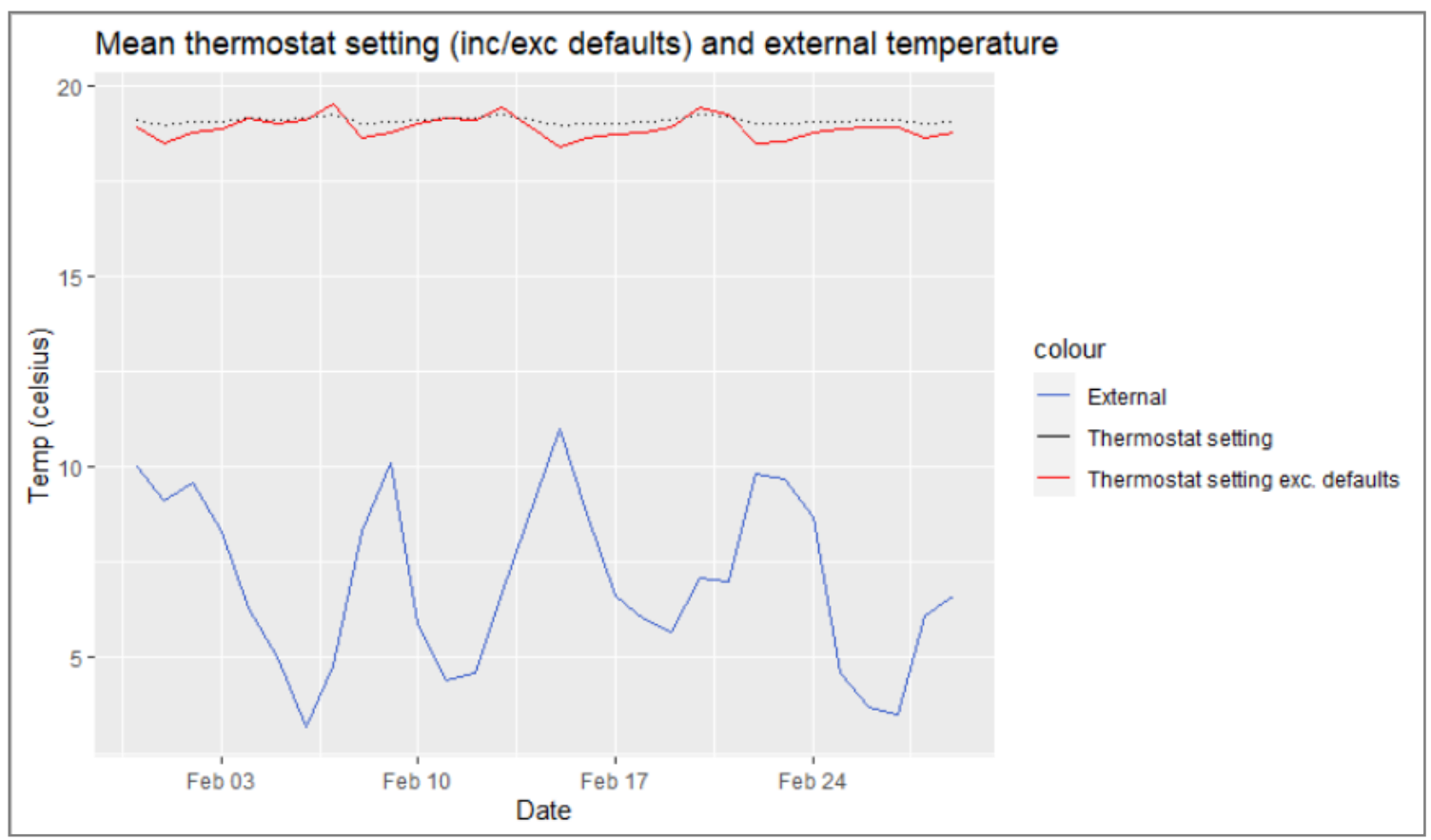

Peaks in external temperature can be seen to coincide with decreases in thermostat setting and result in a significant and meaningful negative correlation $(r=-.56$; $\left.\mathrm{p}=.001 ; \mathrm{Cl}_{95}[-.77-.25]\right)$. Thus, external temperature was included as a control variable in subsequent multi-level regression analyses employing time-series temperature data. 
Research questions 1-3: Does the model predict behaviour in this case?

The following section comprises of a series of analyses which answer the main questions posed in the study;

(1) Is the CADM predictive of pro-environmental behaviours?

(2) Is the CADM predictive of results of the experimental manipulation?

(3) To what extent do moral values about the environment predict PEB's?

Answering these questions requires the same type of analyses and so for parsimony they are presented together.

The association between demographic variables (i.e., gender, age, ethnicity, political orientation) and mean thermostat setting were tested in individual regressions. None of the demographic variables were significant. Being born in the UK, however, was significantly correlated with lower thermostat setting overall $(b=-1.03[-1.79-0.27], t(84)=$ $-2.71, p=.008)$. While interesting, this effect was not predicted thus we draw no strong conclusions from it here, and may be of interest for future research in this area.

The measured variables in this study are related to those of the CADM as laid out in Table 1 (p13). A measure of the CADM's utility in this context is the extent to which it predicts a pro-environmental behaviour from the measured variables. Correlations were calculated for each variable against the factors of behavioural intentions (Activist and Pragmatist) plus the actual PEB (thermostat setting), and compared to the CADM equivalent.

An overview of the bivariate correlations can be seen in Figure 8 . Broadly, it is apparent that there are a number of relatively strong correlations between variables measured via the survey (labelled in red), but much smaller effects between survey variables and the actual pro-environmental behaviours of interest (green). The only 
notable exception was with Attitude which had a medium-sized negative correlation with mean thermostat setpoint.

FIGURE 7: BI-VARIATE CORRELATIONS OF SURVEY VARIABLES AND MEASURED PRO-ENVIRONMENTAL BEHAVIOUR

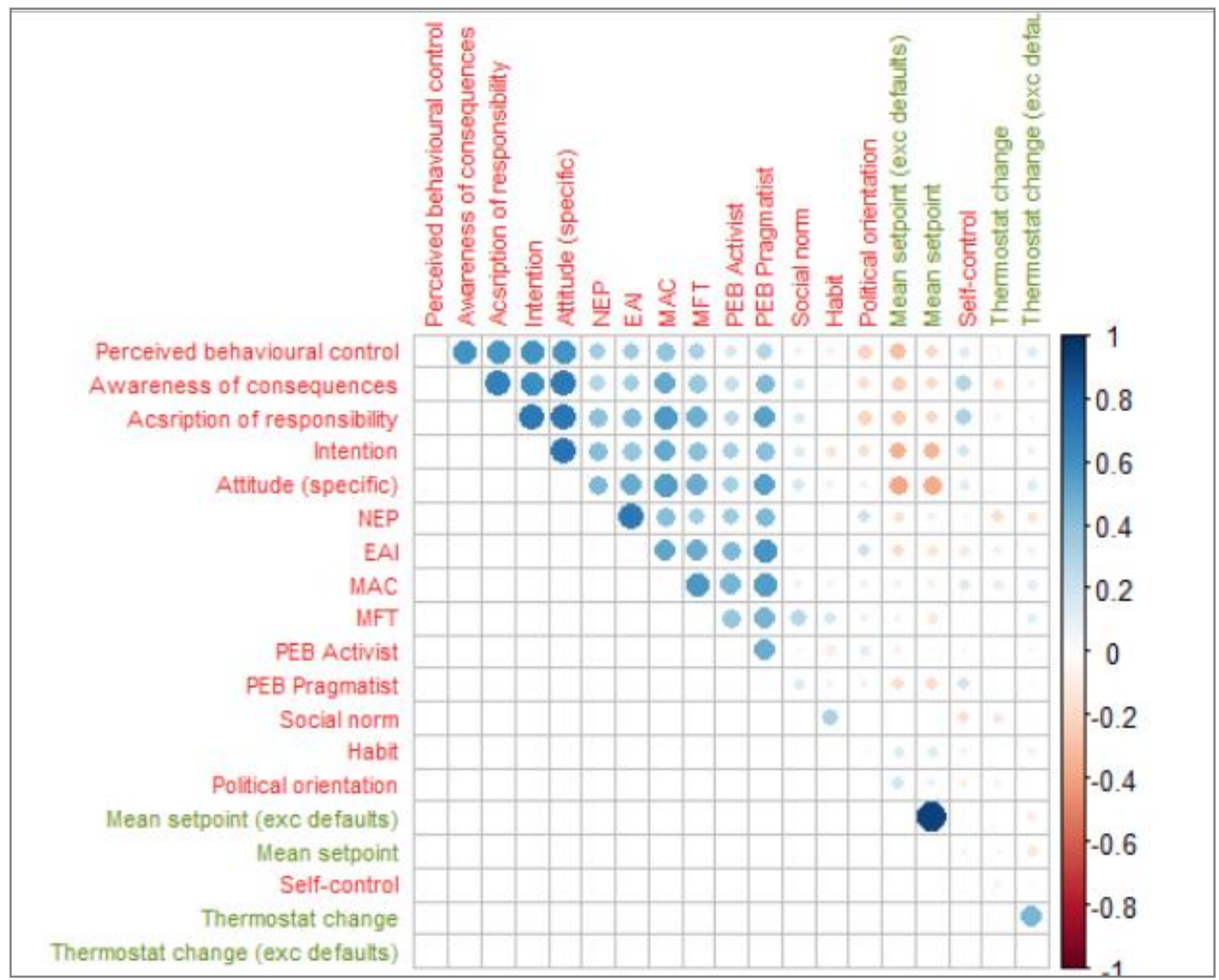

The comparison of correlations with the actual PEB, as measured by the average thermostat setting (exc. defaults), are listed in Table 5. Only one PEB measure was used to compare correlations as thermostat change effect size was insignificant and the data including default was largely equivalent. Instances where the magnitude of the correlation is in line with the CADM are highlighted in bold, with p-values based on the differences between data in this study and that of the CADM. Attitude, Intentions and Perceived Behavioural Control and NEP all showed positive, small-medium effect sizes within the 95\% CI predicted by the CADM. In addition both Ascription of Responsibility and Intentions also showed small-medium effect sizes, albeit outside of the confidence intervals predicted. 
TABLE 5: ACTUAL THERMOSTAT SETTING BEHAVIOUR CORRELATIONS \& COMPARISON WITH CADM BEHAVIOUR VARIABLE

\begin{tabular}{lllll}
\hline Variable & $\begin{array}{l}\text { Correlation } \\
{[95 \% \mathrm{Cl}]}\end{array}$ & $\begin{array}{l}\text { CADM } \\
\text { correlation } \\
{[95 \% \mathrm{Cl}]}\end{array}$ & $\begin{array}{l}\text { Correlation } \\
\text { within CADM } \\
\mathrm{Cl} \text { ? }\end{array}$ & $\begin{array}{l}\text { P value of } \\
\text { correlation } \\
\text { difference }\end{array}$ \\
\hline Awareness of consequences (AC) & $.23[.42 .02]$ & $.22[.17 .28]$ & Yes & .92 \\
Ascription of responsibility (AR) & $.25[.04 .43]$ & $.10[.03 .17]$ & No (higher) & .17 \\
NEP & $.14[-.07 .35]$ & $.09[.03 .15]$ & Yes & .62 \\
Social norm (SN) & $.00[-.21 .22]$ & $.24[.18 .30]$ & No & .03 \\
Perceived behavioural control & $.31[.10 .48]$ & $.40[.29 .50]$ & Yes & .33 \\
(PBC) & & & & \\
Habits (HAB) & $-.12[-.32 .09]$ & $.46[.26 .62]$ & No & $<.001$ \\
Intentions (INT) & $.36[.15 .53]$ & $.55[.47 .63]$ & No & .02 \\
Attitude (ATT) & $.39[.19 .55]$ & $.36[.28 .43]$ & Yes & .78 \\
Brief Self-Control Scale (BSCS) & $.03[-.19 .23]$ & & & \\
Morality as co-operation (MAC) & $-.06[-.27 .15]$ & & & \\
Moral Foundations (MFT) & $.07[-.15 .27]$ & & & \\
\hline
\end{tabular}

Note: A positive correlation with pro-environmental behaviour equates to a lower thermostat setting

Both Habit and Social Norm were notably absent as correlates to behaviour, with Habit actually showing a small negative correlation with the PEB. Overall however, these bivariate correlations show some positive evidence for the utility of the CADM. Of particular interest is the correlation of PEB with Attitude.

To fully utilise the power of the time-series data available from the thermostat control system, mixed effect linear regression models were conducted predicting the four defined PEBs. These included external temperature as a control, and a random-intercept for participant to account for the repeated measures. Employing these models on the longitudinal data, treated each participant as a random effect, and control for time thus appropriately accounting for within and between individual differences in thermostat setting.

To avoid unnecessary repetition only the sets of models using thermostat data excluding defaults is presented as the results for both sets of analyses were consistent. Table 6 (p32) shows the models run on data from 551 rooms and Table 7 shows the models run on data from the 86 rooms whose occupants completed the survey. Equivalent tables for the dataset including default settings can be found in Appendix. Given the large 
amount of data employed in these analyses, any non-zero effects are expected to be statistically significant. And thus, inferences are predominantly focused on the size of the estimated coefficients.

Model 1 indicates that thermostat setting did not vary significantly with time. Model 2 added external temperature as a covariate which is seen to have a small effect on average thermostat setting. When external temperature increased by 1 SD thermostat setting decreased by between $0.05-0.09^{\circ} \mathrm{C}$ (measurement with and without default settings included). In Model 3, an index variable of whether the temperature setting was measured before the manipulation (Day 0 to 14) or after (Day 15 onwards) was included. This showed in both cases that the manipulation did not have an overall significant effect. In Model 4, fixed effect covariate of framing condition (Warneford = Generic; Crescent = Family) was included and we see no reliable difference in average temperature settings between them. Lastly, Model 5 estimated whether the manipulation had a different effect in each of the residence halls, testing the focal hypothesis of the potential of differing effectiveness of 'family' vs 'generic' moral calls to action on thermostat settings. The results of this model indicate that when all rooms are considered the effect of the manipulation was significantly stronger (i.e. lead to greater reductions in thermostat setting) in the 'generic' condition compared to the family condition - although again the average estimated decrease in thermostat setting was very small at around -0.08 to -0.09 ${ }^{\circ} \mathrm{C}$. Critically, however the effect of the manipulation in the sub-sample of questionnaire respondents (Table 7) was not seen to decrease the average thermostat setting and thus the effect of the experimental manipulation could not be used as a PEB. 
TABLE 6: MIXED MODEL REGRESSION RESULTS MEAN SETPOINT IN ${ }^{\circ} \mathrm{C}$ EXCLUDING DEFAULT SETTINGS

\begin{tabular}{|c|c|c|c|c|c|c|c|c|c|c|c|c|c|c|c|}
\hline \multirow[b]{2}{*}{ Predictors } & \multicolumn{3}{|c|}{ Model 1} & \multicolumn{3}{|c|}{ Model 2} & \multicolumn{3}{|c|}{ Model 3} & \multicolumn{3}{|c|}{ Model 4} & \multicolumn{3}{|c|}{ Model 5} \\
\hline & Estimates & $\mathrm{Cl}$ & $p$ & Estimates & $\mathrm{Cl}$ & $p$ & Estimates & $\mathrm{Cl}$ & $p$ & Estimates & $\mathrm{Cl}$ & $p$ & Estimates & $\mathrm{Cl}$ & $p$ \\
\hline (Intercept) & 20.07 & $\begin{array}{c}19.86- \\
20.28\end{array}$ & $<0.001$ & 20.09 & $\begin{array}{c}19.88- \\
20.30\end{array}$ & $<0.001$ & 20.08 & $\begin{array}{c}19.87- \\
20.29\end{array}$ & $<0.001$ & 20.21 & $\begin{array}{c}19.92- \\
20.49\end{array}$ & $<0.001$ & 20.19 & $\begin{array}{c}19.90- \\
20.47\end{array}$ & $<0.001$ \\
\hline Day & 0.00 & $\begin{array}{c}-0.00- \\
0.00\end{array}$ & 0.262 & -0.00 & $\begin{array}{c}-0.00- \\
-0.00\end{array}$ & 0.002 & 0.00 & $\begin{array}{c}-0.00- \\
0.00\end{array}$ & 0.953 & 0.00 & $\begin{array}{c}-0.00- \\
0.00\end{array}$ & 0.948 & -0.00 & $\begin{array}{c}-0.00- \\
0.00\end{array}$ & 0.884 \\
\hline External temp & & & & -0.09 & $\begin{array}{c}-0.09- \\
-0.08\end{array}$ & $<0.001$ & -0.08 & $\begin{array}{c}-0.09- \\
-0.08\end{array}$ & $<0.001$ & -0.08 & $\begin{array}{c}-0.09- \\
-0.08\end{array}$ & $<0.001$ & -0.08 & $\begin{array}{c}-0.09- \\
-0.08\end{array}$ & $<0.001$ \\
\hline Manipulation & & & & & & & -0.02 & $\begin{array}{c}-0.05- \\
0.00\end{array}$ & 0.059 & -0.02 & $\begin{array}{c}-0.05- \\
0.00\end{array}$ & 0.058 & 0.02 & $\begin{array}{c}-0.01- \\
0.05\end{array}$ & 0.171 \\
\hline $\begin{array}{l}\text { Condition } \\
\text { [Generic] }\end{array}$ & & & & & & & & & & -0.28 & $\begin{array}{c}-0.71- \\
0.14\end{array}$ & 0.194 & -0.23 & $\begin{array}{c}-0.66- \\
0.19\end{array}$ & 0.284 \\
\hline $\begin{array}{l}\text { Manipulation * } \\
\text { Condition } \\
\text { [Generic] }\end{array}$ & & & & & & & & & & & & & -0.09 & $\begin{array}{c}-0.12- \\
-0.07\end{array}$ & $<0.001$ \\
\hline \multicolumn{16}{|l|}{ Random Effects } \\
\hline $\mathrm{N}$ & \multicolumn{2}{|l|}{551 site_room } & \multicolumn{3}{|c|}{551 site_room } & \multicolumn{3}{|c|}{551 site_room } & \multicolumn{3}{|c|}{551 site_room } & \multicolumn{3}{|c|}{551 site_room } & \\
\hline Observations & \multicolumn{2}{|l|}{114314} & \multicolumn{3}{|c|}{114314} & \multicolumn{3}{|c|}{114314} & \multicolumn{3}{|c|}{114314} & \multicolumn{3}{|c|}{114314} & \\
\hline $\begin{array}{l}\text { Marginal } R^{2} / \\
\text { Conditional } R^{2}\end{array}$ & \multicolumn{2}{|c|}{$0.000 / 0.859$} & \multicolumn{3}{|c|}{$0.001 / 0.860$} & \multicolumn{3}{|c|}{$0.001 / 0.860$} & \multicolumn{3}{|c|}{$0.004 / 0.860$} & \multicolumn{3}{|c|}{$0.004 / 0.859$} & \\
\hline
\end{tabular}


TABLE 7: MIXED MODEL RESULTS FOR SURVEY PARTICIPANTS (MEAN SETPOINT IN ${ }^{\circ} \mathrm{C}$ EXCLUDING DEFAULTS)

\begin{tabular}{|c|c|c|c|c|c|c|c|c|c|c|c|c|c|c|c|}
\hline \multirow[b]{2}{*}{ Predictors } & \multicolumn{3}{|c|}{ Model 1} & \multicolumn{3}{|c|}{ Model 2} & \multicolumn{3}{|c|}{ Model 3} & \multicolumn{3}{|c|}{ Model 4} & \multicolumn{3}{|c|}{ Model 5} \\
\hline & Estimates & $\mathrm{Cl}$ & $p$ & Estimates & $\mathrm{Cl}$ & $p$ & Estimates & $\mathrm{Cl}$ & $p$ & Estimates & $\mathrm{Cl}$ & $p$ & Estimates & $\mathrm{Cl}$ & $p$ \\
\hline (Intercept) & 19.61 & $\begin{array}{c}19.23- \\
20.00\end{array}$ & $<0.001$ & 19.63 & $\begin{array}{c}19.24- \\
20.01\end{array}$ & $<0.001$ & 19.65 & $\begin{array}{c}19.27- \\
20.04\end{array}$ & $<0.001$ & 19.51 & $\begin{array}{c}18.97- \\
20.05\end{array}$ & $<0.001$ & 19.49 & $\begin{array}{c}18.95- \\
20.03\end{array}$ & $<0.001$ \\
\hline Day & 0.00 & $\begin{array}{c}-0.00- \\
0.01\end{array}$ & 0.602 & 0.00 & $\begin{array}{c}-0.01- \\
0.01\end{array}$ & 0.889 & -0.01 & $\begin{array}{c}-0.02- \\
0.01\end{array}$ & 0.337 & -0.01 & $\begin{array}{c}-0.02- \\
0.01\end{array}$ & 0.337 & -0.01 & $\begin{array}{c}-0.02- \\
0.01\end{array}$ & 0.333 \\
\hline External temp & & & & -0.06 & $\begin{array}{c}-0.10- \\
-0.01\end{array}$ & 0.017 & -0.06 & $\begin{array}{c}-0.11- \\
-0.01\end{array}$ & 0.011 & -0.06 & $\begin{array}{c}-0.11- \\
-0.01\end{array}$ & 0.011 & -0.06 & $\begin{array}{c}-0.11- \\
-0.01\end{array}$ & 0.011 \\
\hline Manipulation & & & & & & & 0.11 & $\begin{array}{c}-0.07- \\
0.29\end{array}$ & 0.232 & 0.11 & $\begin{array}{c}-0.07- \\
0.29\end{array}$ & 0.233 & 0.15 & $\begin{array}{c}-0.05- \\
0.35\end{array}$ & 0.142 \\
\hline $\begin{array}{l}\text { Condition } \\
\text { [Generic] }\end{array}$ & & & & & & & & & & 0.29 & $\begin{array}{c}-0.46- \\
1.04\end{array}$ & 0.448 & 0.33 & $\begin{array}{c}-0.43- \\
1.09\end{array}$ & 0.393 \\
\hline $\begin{array}{l}\text { Manipulation * } \\
\text { Condition } \\
\text { [Generic] }\end{array}$ & & & & & & & & & & & & & -0.08 & $\begin{array}{c}-0.26- \\
0.10\end{array}$ & 0.375 \\
\hline
\end{tabular}

\section{Random Effects}

\begin{tabular}{lllll}
$\mathrm{N}$ & 86 Responseld & 86 Responseld & 86 Responseld & 86 Responseld \\
\hline Observations & 1960 & 1960 & 1960 & 1960 \\
Marginal $R^{2} /$ & $0.000 / 0.753$ & $0.001 / 0.753$ & $0.001 / 0.753$ & $0.006 / 0.755$ \\
Conditional $R^{2}$ & & & $0.006 / 0.755$
\end{tabular}


Next, the relationship between focal predictor variables from the questionnaire and the actual pro-environmental behaviour of thermostat setting were examined in a series of mixed-effect linear regressions. No reliable association was observed between behavioural intentions (Activist or Pragmatist), broad moral attitude (MAC/MFT), broad environmental attitudes (EAI, NEP), Habits, Social Norm or Self-control and thus these models are not presented here. These more powerful and robust statistical tests confirm the bivariate correlation analyses presented earlier that these variables are unrelated to thermostat settings in this sample. However, significant and meaningful main effects were found with Attitude, Intention, Perceived Behavioural Control and Awareness of Consequences (Table 9, p36). As shown previously, strong bivariate correlations were observed between these variables (Figure 8, p27) and when modelled together in a multiple regression to account for their covariance, the effect of moral attitude was observed to have the strongest independent relationship with actual thermostat control behavior, followed by Intention.

TABLE 8: MULTI-LEVEL LINEAR REGRESSION OF VALUES, ATTITUDES AND BELIEFS

\begin{tabular}{|c|c|c|c|}
\hline \multirow[b]{2}{*}{ Predictors } & \multicolumn{3}{|c|}{$\begin{array}{l}\text { Mean setting }\left({ }^{\circ} \mathrm{c}\right) \\
\text { EXCL defaults }\end{array}$} \\
\hline & Estimates & $\mathrm{Cl}$ & $p$ \\
\hline (Intercept) & 19.63 & $19.28-19.99$ & $<0.001$ \\
\hline Attitude & -0.63 & $-1.26-0.00$ & 0.051 \\
\hline PBC & -0.23 & $-0.70-0.24$ & 0.338 \\
\hline Intention & -0.36 & $-0.93-0.21$ & 0.215 \\
\hline Awareness of consequences & 0.46 & $-0.17-1.08$ & 0.150 \\
\hline Day & 0.00 & $-0.01-0.01$ & 0.880 \\
\hline External temperature & -0.06 & $-0.10--0.01$ & 0.018 \\
\hline \multicolumn{4}{|l|}{ Random Effects } \\
\hline$N_{\text {Responseld }}$ & 86 & & \\
\hline Observations & 1960 & & \\
\hline
\end{tabular}


In summary, there is some evidence in this study for the predictive utility of the CADM. Of the eight predictor variables, four show correlations within the $95 \%$ confidence intervals for the actual PEB and a further two show notable effect sizes although outside of those confidence intervals. On the other hand, neither Social Norm nor Habit played a role in predicting behaviour. Specific moralised attitudes were seen to be the strongest influence on pro-environmental behaviour. From the mixed-effect models it is clear that the experimental manipulation did not have the hypothesized effect of producing a measurable change in behaviour and potential reasons for this are considered in the discussion. 
TABLE 9: MIXED EFFECT MODELS OF VALUES, ATTITUDES AND BELIEFS WITH REGARD TO THERMOSTAT SETTING

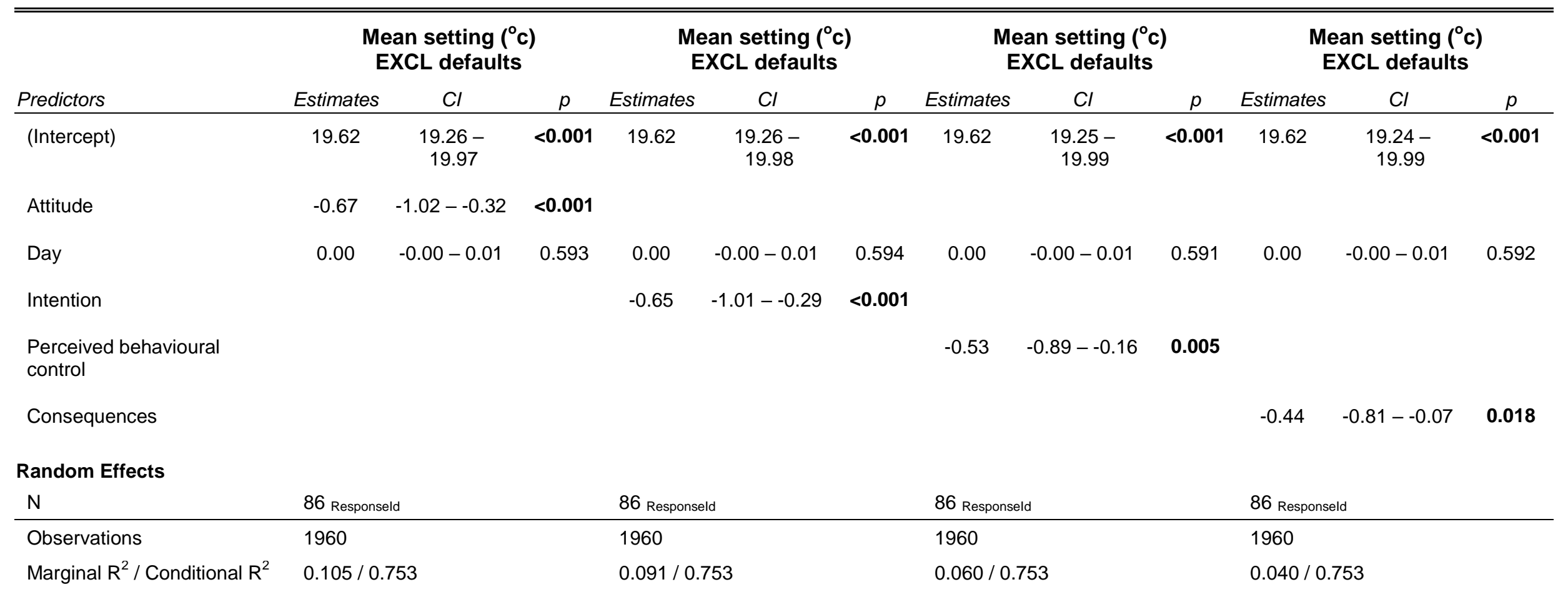


Research question 4: Does self-control help explain pro-environmental behaviour?

As can be seen from correlations (Figure 8, p27), mixed model results and the linear regression results in Table 10, there was no observed correlation of self-control with overall thermostat set-point or changes in thermostat control behaviour after the manipulation.

TABLE 10: SELF-CONTROL DOES NOT CORRELATE WITH PEB

\begin{tabular}{|c|c|c|c|c|c|c|}
\hline \multirow[b]{2}{*}{ Predictors } & \multicolumn{3}{|c|}{$\begin{array}{l}\text { Mean setpoint } \\
\text { (centered, }{ }^{\circ} \mathrm{c} \text { ) }\end{array}$} & \multicolumn{3}{|c|}{$\begin{array}{l}\text { Mean setpoint after manipulation } \\
\left(\text { centered, }{ }^{\circ} \mathrm{c}\right)\end{array}$} \\
\hline & Estimates & $\mathrm{Cl}$ & $p$ & Estimates & $\mathrm{Cl}$ & $p$ \\
\hline (Intercept) & -0.11 & $-0.33-0.11$ & 0.311 & 0.04 & $-0.28-0.36$ & 0.816 \\
\hline Brief Self-Control Scale & 0.06 & $-0.16-0.28$ & 0.584 & -0.04 & $-0.34-0.26$ & 0.784 \\
\hline $\begin{array}{l}\text { Mean setpoint before } \\
\text { manipulation (centered, }{ }^{\circ} \mathrm{C} \text { ) }\end{array}$ & & & & 0.73 & $0.58-0.89$ & $<0.001$ \\
\hline Observations & \multicolumn{3}{|l|}{86} & \multicolumn{3}{|c|}{86} \\
\hline$R^{2} / R^{2}$ adjusted & \multicolumn{3}{|c|}{$0.004 /-0.008$} & \multicolumn{3}{|c|}{$0.532 / 0.520$} \\
\hline
\end{tabular}

Research question 5: What is the relative performance of the EAI vs. NEP?

Best fit regression lines are shown for both NEP and EAI versus the specific moral attitudes towards thermostat control in Figure 9. The bi-variate relationships are very similar for NEP $\left(r=0.43, \mathrm{Cl}_{95}=[.24 .59]\right)$, compared to EAI $\left(r=.46, \mathrm{Cl}_{95}=[.28 .61]\right)$. NEP and EAI are clearly very highly correlated $\left(r=.71, \mathrm{Cl}_{95}=[.59 .80], \mathrm{p}<.001\right)$.

Similarly, no significant difference was found between the two scales and the behavioural intentions scale $\left(r_{\mathrm{NEP}}=.47[.29 .62] ; r_{\mathrm{EAI}}=.61[.46 .73] ; p_{\text {diff }}=0.21\right)$. 
Attitude towards thermostat usage was measured against NEP and EAI to test their comparative association. Linear regression showed that EAI was the superior predictor of thermostat Attitude (Table 11) which is of interest given the importance of a moralised attitude in predicting behaviour. However, there was no evidence of either NEP or EAI having any meaningful correlation with actual behaviour (Table 12).

FIGURE 8: NEP AND EAI VARIATION WITH (THERMOSTAT SPECIFIC) ATTITUDE

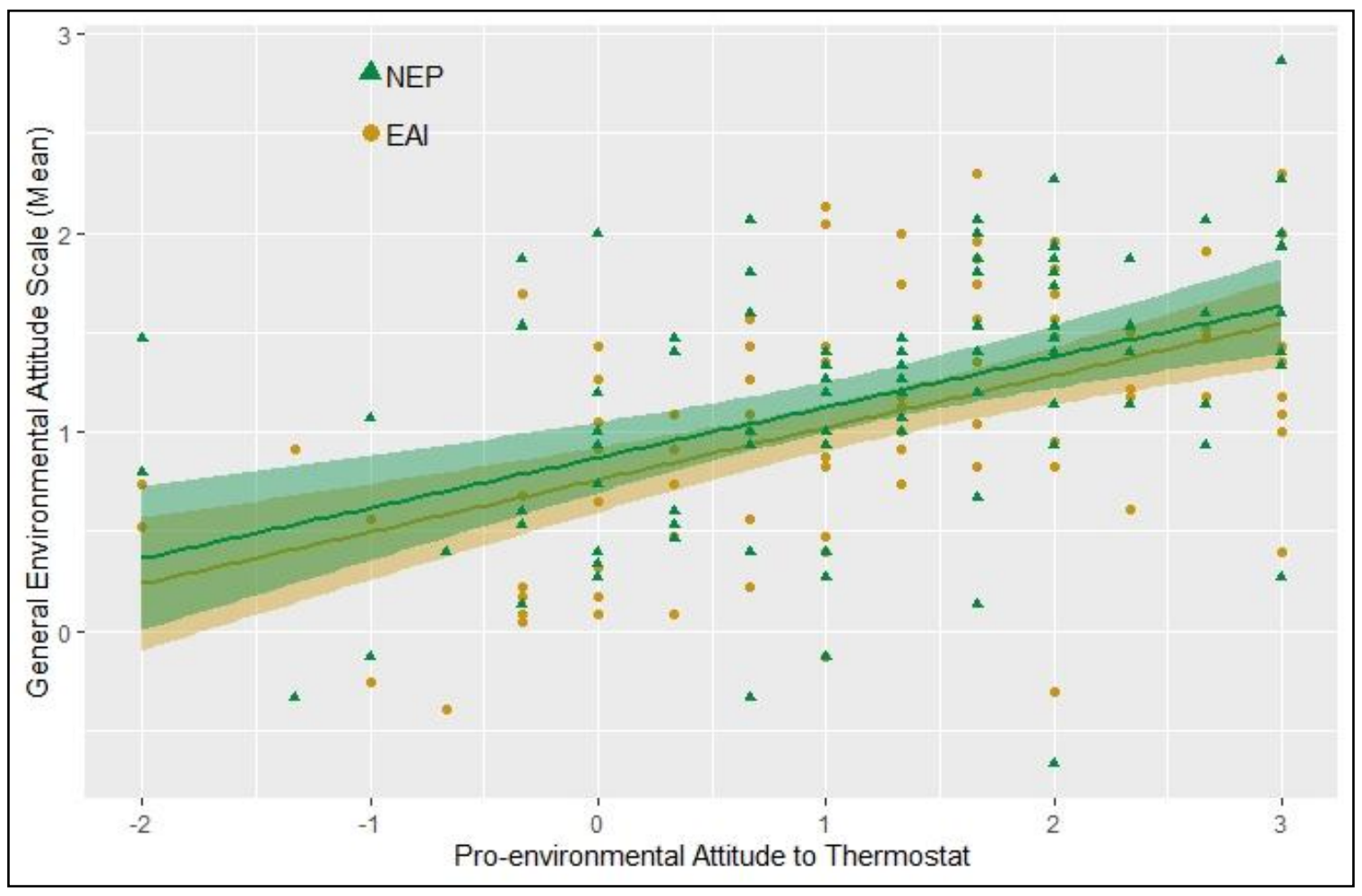


TABLE 11: REGRESSION RESULTS OF BROAD ENVIRONMENTAL ATTITUDE TO THERMOSTAT SPECIFIC ATTITUDE

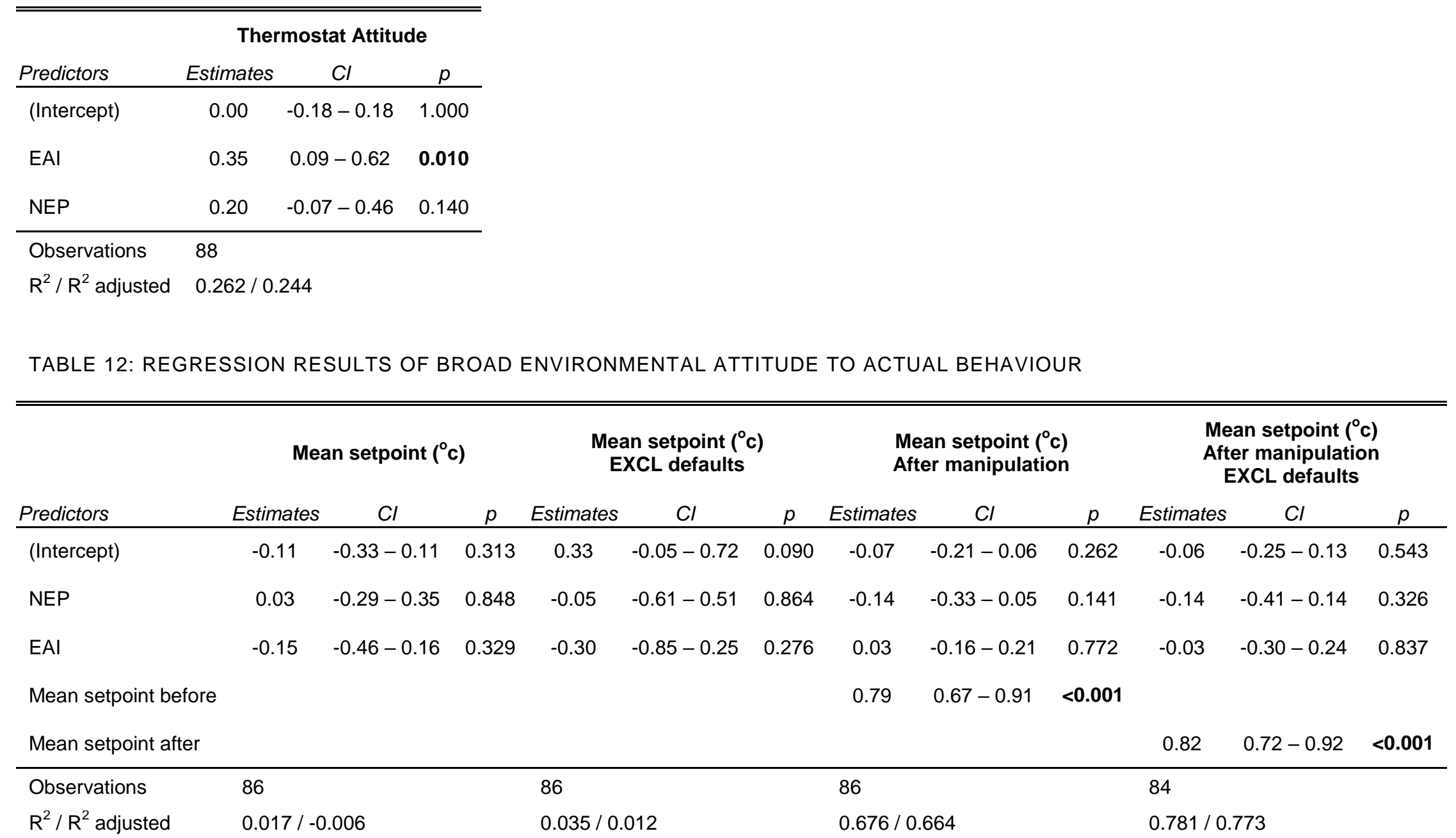




\section{DISCUSSION}

This study had two primary goals: to evaluate the validity of an existing theoretical model of pro-environmental behaviour with a real-world PEB, and to establish causality through an experimental intervention to reduce thermostat settings. In so doing, the study described in this dissertation makes an important contribution to the literature by comprehensively linking behavioural data to values, attitudes and beliefs, combined with an experimental manipulation. Previous research has noted the need for exactly this type of research (e.g., Ellemers et al., 2019; Gifford, 2014).

Overall, this research provides some support for the predictive utility of the CADM (Klöckner, 2013), importantly more so with actual rather than intended behaviour. Some factors in the model, however, did not reliably predict behaviour. For example, social norms had no association with behaviour, which may be due to the fact that the behaviour is unobserved (despite being recorded by the university). There is evidence that observability is a factor in environmental behaviours which come with a cost (Vesely \& Klöckner, 2018), with the cost in this case being the cognitive and physical effort of changing ones thermostat setting. It has been shown that visible feedback on energy usage can positively impact pro-environmental behaviour (Zhuang \& Wu, 2019) thus, an interesting avenue of future research might be to test the effect of usage feedback in this context.

Habits, although prominent in the CADM, were not correlated with behaviour in this study, despite evidence to contrary in other studies (Carrington et al., 2012; Ouellette \& Wood, 1998). In fact it showed a small (non-significant) negative correlation. This may be due to the fact that in this particular situation the habit of adjusting ones thermostat can be pro- or anti-environmental. With regards to other pro-environmental behaviours, they are typically done (pro-environmental action) or not done (e.g. recycling, eating vegetarian). In these cases, which are more frequently studied in the literature, the repeated action can 
only increase the pro-environmental outcome. However in this study, participants that habitually adjust their thermostats may be doing so to set their thermostat at a higher temperature - prioritising personal comfort over environmental concerns. And thus, the operationalisation of habits in the current study may very well be testing a different hypothesis than that proposed by the CADM.

Variables from the CADM which did show a correlation with behaviour in this analysis were Intentions, Ascription of Responsibility, Awareness of Consequences, NEP, Perceived Behavioral Control, and Attitude, of which the last four were also within the effect size range predicted by the model. Of particular interest is Attitude as it was the largest predictor of PEB in the entire dataset. In this research, six of eight predictor variables showed small/medium size correlations with the PEB and there are plausible reasons which may explain why the remaining two did not, so overall the CADM performed very respectably in predicting behaviour.

Examining the Attitude variable more critically, it is questionable in retrospect whether the variable as measured in this research accurately reflects what was intended in the CADM. Attitudes, as defined by the Theory of Planned Behaviour (Ajzen, 1988), are "a general measure of the favourability a behavioural alternative has for an individual". In retrospect a measure of attitude should therefore have included an assessment from each participant of their overall favourability of lowering or increasing their thermostat setting, rather than just statements regarding morality of thermostat usage. This would have drawn out the tensions between personal comfort and the pro-environmental behaviour. The findings remain interesting however because of their clear influence on behaviour of what might more accurately be termed "Moral Attitude". This relationship supports the hypothesis that moralising a behaviour is an important factor in predicting actual behaviour (Atran, 2016). If the study were to be repeated, a more accurate representation of Attitude could be used, alongside the Moral Attitude statements. 
The impact of increasing Moral Attitude towards the behaviour are potentially very high. Potential savings in cost and carbon emissions based on current usage were used to estimate differences in temperature that would be meaningful. Crescent and Warneford Halls each use around 900,000 kWh's a year of electricity. This equates to a total of $£ 234 k$ p.a. and $\mathrm{CO}_{2}$ emissions of around 460 tonnes a year. There is little systematic evidence of the size of effect of reducing thermostat settings on energy consumption (Munton et al., 2014). One estimate is that reducing a domestic thermostat setting from $19^{\circ} \mathrm{C}$ to $18^{\circ} \mathrm{C}$ would result in a 13\% decrease in energy used (Palmer et al., 2012). This estimate is taken for a typical domestic property rather than a student room, but no specific estimates could be found for student accommodation. Oxford Brookes Chartered Energy Manager quoted an industry typical figure of $5 \%$ energy saving for a $0.5^{\circ} \mathrm{C}$ decrease (G. Hodgson, personal communication, 16 June, 2020), which is broadly in keeping with the previous estimate. Thus, a $5 \%$ decrease in energy usage could equate to savings of $£ 11,700$ per annum and save $23 \mathrm{t}$ of $\mathrm{CO}_{2}$. Therefore a reduction of $0.5^{\circ} \mathrm{C}$ can be taken to be a meaningful effect size. The results of the mixed-effect models predicting thermostat setting (excluding defaults) indicate that a standard deviation increase in Moral Attitude was associated with a -0.32 to -1.02 degree change in thermostat setting across the time period (Table 9, p36). And thus, if there was a way to increase this moralised concern by 1 SD, it could result in savings for Oxford Brookes of between $£ 7,500-£ 24,000$ and 150 $470 \mathrm{t} \mathrm{CO}_{2}$ per annum. Further, if a $0.32^{\circ} \mathrm{C}$ drop in thermostat setting is approximated to a $0.3 \%$ drop in energy usage and this replicated across the whole the UK domestic home heating usage (Waters, 2019) it would equate to savings of $£ 617 \mathrm{~m}$ or 13.6 million tonnes of $\mathrm{CO}_{2}$ (Appendix 3). Of interest for future research then would be to investigate the factors which cause this, or any, PEB to become moralised.

Thinking about what might increase moralisation of this issue within Values-BeliefsNorms theory (Stern, 2000a) leads to thinking about the antecedent variables, as per the structure of the CADM - one thing leads to another. But these are rational models, which 
use a logical, deterministic paradigm, and it has been shown that personal moral values do not stem from deliberate, rational human reasoning. Rather, reason is more often employed post-rationally to justify moral intuitions which people sometimes struggle to explain (Graham et al., 2011). This study, as with many more before it (e.g., Kollmuss \& Agyeman, 2002), demonstrates that behavioral intentions correlate only mildly with behaviour itself. As such, perhaps the very idea of an intention-behaviour gap represents an incorrect, or perhaps incomplete, framing of this problem. Are explicit, highly cognitively processed attitudes, converted into mentalese (Tillas, 2015), filtered for social and personal acceptability really part of the same system which produces behaviour? All of this may indicate the origins of a "what becomes a moral issue" for an individual is deserving of a broader, more holisitic investigation than simply looking to prior cause in a rational choice model.

One important factor across the analyses was the effect of the centralised defaults. As previously noted this exerted a large effect on the thermostat data and so how it has been dealt with in the analysis is important when considering results. Methodologically, it could be argued that excluding default observations from analysis is problematic as this reduces the external validity of the data. The decision not to deviate from the defaults is itself a behaviour and further, default settings could coincidentally be what a room occupant would have chosen anyway. However, it is not possible to distinguish from the available data observations which represent a default setting that was actively chosen, one which was passively accepted, or one which the participant was entirely unaware of. For example, default settings will have accounted for all observations when the participants were asleep or when absent from their rooms entirely. These observations should not be expected to count in a model of behaviour, but are impossible to identify. Figure 10 shows how the proportion of default setting observations varied by individual room. This demonstrates the overall dominance of default settings, but it also shows that most participants did not rely on them exclusively. Indeed, the vast majority of occupants 
interacted with the thermostat, with 550 of the 552 rooms (99.6\%) showing some level of deviance from the defaults. Thus it can be inferred that for most, if a room was kept at default level it was because the user was happy with that temperature. However, the power of defaults in general (e.g., Tversky \& Kahneman, 1991) and for environmental behaviour has been shown e.g. for green electricity provision (Pichert \& Katsikopoulos, 2008). Thus, it is likely that the default program will have dampened behavioural variation to some extent. As a result, to have conducted the analyses with and without the default settings included seems reasonable and appropriate.

FIGURE 9: WHILST DEFAULT SETTINGS ARE HIGHLY PREVALENT, MOST PARTICIPANTS DO NOT RELY SOLELY ON THEM

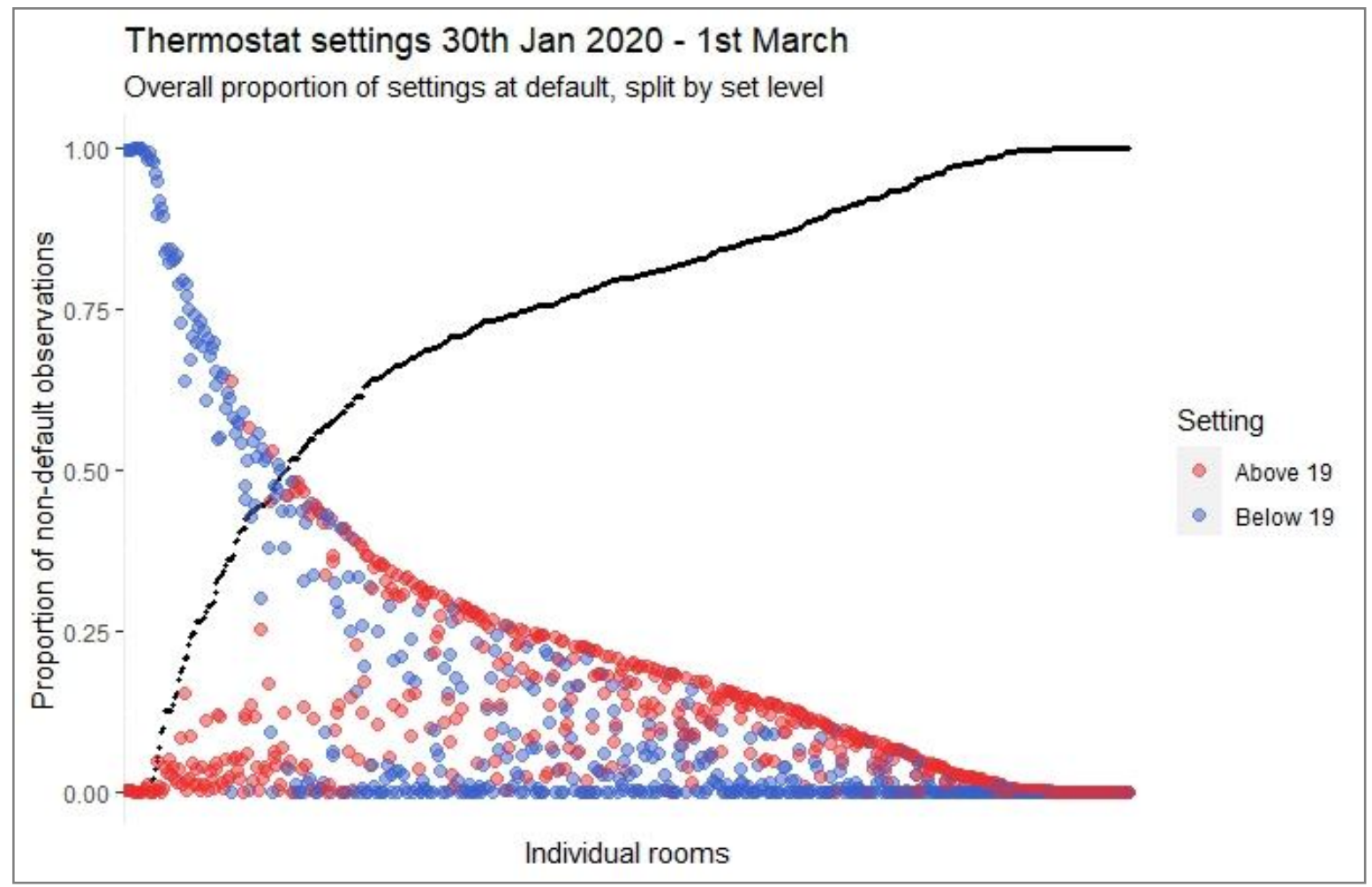

Note: Low proportions of default reliance were associated with colder thermostat settings. This is as expected given that the default program leaves any setting below $19^{\circ} \mathrm{C}$ unchanged indefinitely, whereas higher temperature settings are over-ridden after 3 hours and returned to the defaults.

With regard to the experimental intervention, the expected effect of increased PEB (lower thermostat setting) was not observed. This could be because the intervention itself, as a communications only exercise was not sufficient to produce behaviour change. It has 
been shown that effecting pro-environmental behaviour change normally requires a much more holisitic approach than simply presenting a piece of communication (Abrahamse et al., 2005; Steg \& Vlek, 2008). Alternatively, it could be that the communications themselves were ineffective; perhaps the Australian bush-fires were regarded as irrelevant given their geographical distance. It is interesting to note that the 'family' moral framing produced less positive results then the 'generic' frame, suggesting that this choice of framing may not have resonated with the target audience - young university students. Importantly, it does show that the type of moral framing made a difference to the response. Having some follow-up qualitative research to understand participants' reaction to the communications may have been a useful addition to the study.

Having considered the main results, the research also investigated the role of selfcontrol, as well as the relative merits of the NEP scale versus the EAI. The research does not provide any evidence for the effect of self-control on this particular pro-environmental behaviour. A lack of positive evidence is not, per se, evidence against the hypothesis as this depends on the power of the original study, but no association was found on this occasion. However, it is worth noting that the evidence for this association between selfcontrol and the attitude-behaviour gap was calculated from self-report questionnaire responses, rather than actual behaviour (Redondo \& Puelles, 2017). As a result, there is a reasonable basis to be sceptical of the effect of self-control in original study on the basis of external validity. Finally, despite criticism of the NEP (Hawcroft \& Milfont, 2010) this study provides evidence that benefits of replacing it with EAI are marginal and thus researchers may wish to continue using NEP given its longer history and comparability across other studies. 


\section{CONCLUSION}

In summary, this research adds valuable evidence to the study of pro-

environmental behaviours. It lends support to the Comprehensive Action Determination Model, but also points to the idea that moralising is a crucial part of what drives behaviour. The intention-action gap is clearly observed in this case by the lack of correlation of behavioural intention with pro-environmental behaviour. Future research should be focused on exploring what factors lead an individual to moralise a behaviour or not as this seems to be a fundamentally important influence on pro-environmental behaviour. 


\section{REFERENCES}

Abbasi-asl, R., \& Hashemi, S. (2019). Personality and Morality : Role of the Big Five Personality Traits in. 123-128. http://www.behavsci.ir/article_100375.html

Abrahamse, W., Steg, L., Vlek, C., \& Rothengatter, T. (2005). A review of intervention studies aimed at household energy conservation. Journal of Environmental Psychology. https://doi.org/10.1016/j.jenvp.2005.08.002

Ajzen, I. (1988). Attitude, personality, and behavior (p. 175). Open University Press.

Atran, S. (2016). The devoted actor: Unconditional commitment and intractable conflict across cultures. Current Anthropology, 57, S192-S203. https://doi.org/10.1086/685495

Bain, P. G., Milfont, T. L., Kashima, Y., Bilewicz, M., Doron, G., Garoarsdóttir, R. B., Gouveia, V. V., Guan, Y., Johansson, L. O., Pasquali, C., Corral-Verdugo, V., Aragones, J. I., Utsugi, A., Demarque, C., Otto, S., Park, J., Soland, M., Steg, L., González, R., ... Saviolidis, N. M. (2016). Co-benefits of addressing climate change can motivate action around the world. Nature Climate Change, 6(2), 154-157. https://doi.org/10.1038/nclimate2814

Bamberg, S., \& Möser, G. (2007). Twenty years after Hines, Hungerford, and Tomera: A new meta-analysis of psycho-social determinants of pro-environmental behaviour. Journal of Environmental Psychology, 27(1), 14-25. https://doi.org/10.1016/j.jenvp.2006.12.002

BBC News. (2020). Climate change: Australia fires will be "normal" in warmer world - BBC News. BBC News. https://www.bbc.co.uk/news/science-environment-51094919

Black, J. S., Stern, P. C., \& Elworth, J. T. (1985). Personal and Contextual Influences on Household Energy Adaptations. Journal of Applied Psychology, 70(1), 3-21. https://doi.org/10.1037/0021-9010.70.1.3

Bujang, M. A., \& Baharum, N. (2016). Sample Size Guideline for Correlation Analysis. World Journal of Social Science Research, 3(1), 37. https://doi.org/10.22158/wjssr.v3n1p37

Campbell-Arvai, V. (2015). Food-related environmental beliefs and behaviours among university undergraduates a mixed-methods study. International Journal of Sustainability in Higher Education, 16(3), 279-295. https://doi.org/10.1108/IJSHE-062013-0071

Carrington, M. J., Neville, B. A., \& Whitwell, G. J. (2012). Lost in translation: Exploring the ethical consumer intention-behavior gap «? https://doi.org/10.1016/j.jbusres.2012.09.022

Centre for the Study of Existential Risk. (2019). Extreme Risks and the Global Environment. University of Cambridge. https://www.cser.ac.uk/research/extremerisks-and-global-environment/

Corral-Verdugo, V. (1997). Dual "realities" of conservation behavior: Self-reports vs observations of re-use and recycling behavior. Journal of Environmental Psychology, 17(2), 135-145. https://doi.org/10.1006/jevp.1997.0048 
Curry, O. S., Mullins, D. A., \& Whitehouse, H. (2019). Is it good to cooperate?: Testing the theory of morality-as-cooperation in 60 societies. Current Anthropology, 60(1), 47-69. https://doi.org/10.1086/701478

Diekmann, A., \& Preisendörfer, P. (2003). Green and greenback: The behavioral effects of environmental attitudes in low-cost and high-cost situations. In Rationality and Society (Vol. 15, Issue 4, pp. 441-472). https://doi.org/10.1177/1043463103154002

Dunlap, R. (2008). The new environmental paradigm scale: From marginality to worldwide use. In Journal of Environmental Education (Vol. 40, Issue 1, pp. 3-18). https://doi.org/10.3200/JOEE.40.1.3-18

Ellemers, N., van der Toorn, J., Paunov, Y., \& van Leeuwen, T. (2019). The Psychology of Morality: A Review and Analysis of Empirical Studies Published From 1940 Through 2017. Personality and Social Psychology Review, 23(4), 332-366. https://doi.org/10.1177/1088868318811759

Farjam, M., Nikolaychuk, O., \& Bravo, G. (2019). Experimental evidence of an environmental attitude-behavior gap in high-cost situations. Ecological Economics, 166. https://doi.org/10.1016/j.ecolecon.2019.106434

Feinberg, M., \& Willer, R. (2013). The Moral Roots of Environmental Attitudes. Psychological Science, 24(1), 56-62. https://doi.org/10.1177/0956797612449177

Fishbein, M., \& Ajzen, I. (2005). The Influence of Attitudes on Behavior. The Handbook of Attitudes, 173-222. https://doi.org/10.1007/BF02294218

Gifford, R. (2014). Environmental Psychology Matters. Annual Review of Psychology, 65(1), 541-579. https://doi.org/10.1146/annurev-psych-010213-115048

Graham, J., Nosek, B. A., Haidt, J., lyer, R., Koleva, S., \& Ditto, P. H. (2011). Mapping the Moral Domain. Journal of Personality and Social Psychology, 101(2), 366-385. https://doi.org/10.1037/a0021847

Hawcroft, L. J., \& Milfont, T. L. (2010). The use (and abuse) of the new environmental paradigm scale over the last 30 years: A meta-analysis. Journal of Environmental Psychology, 30(2), 143-158. https://doi.org/10.1016/j.jenvp.2009.10.003

Kaiser, F. G., Schultz, P. W., \& Scheuthle, H. (2007). The theory of planned behavior without compatibility? Beyond method bias and past trivial associations. Journal of Applied Social Psychology, 37(7), 1522-1544. https://doi.org/10.1111/j.15591816.2007.00225.x

Karp, D. G. (1996). Values and their effect on pro-environmental behavior. Environment and Behavior, 28(1), 111-133. https://doi.org/10.1177/0013916596281006

Klöckner, C. A. (2013). A comprehensive model of the psychology of environmental behaviour-A meta-analysis. Global Environmental Change, 23(5), 1028-1038. https://doi.org/10.1016/j.gloenvcha.2013.05.014

Kollmuss, A., \& Agyeman, J. (2002). Mind the Gap: Why do people act environmentally and what are the barriers to pro-environmental behavior? Environmental Education Research, 8(3), 239-260. https://doi.org/10.1080/13504620220145401

Kormos, C., \& Gifford, R. (2014). The validity of self-report measures of proenvironmental behavior: A\&nbsp;meta-analytic review. Journal of Environmental Psychology, 40, 
359-371. https://doi.org/10.1016/j.jenvp.2014.09.003

Lange, F., \& Dewitte, S. (2019). Measuring pro-environmental behavior: Review and recommendations. In Journal of Environmental Psychology (Vol. 63, pp. 92-100). Academic Press. https://doi.org/10.1016/j.jenvp.2019.04.009

Lindner, C., Nagy, G., \& Retelsdorf, J. (2015). The dimensionality of the Brief Self-Control Scale-An evaluation of unidimensional and multidimensional applications. Personality and Individual Differences, 86, 465-473. https://doi.org/10.1016/j.paid.2015.07.006

Markowitz, E. M., \& Shariff, A. F. (2012). Climate change and moral judgement. In Nature Climate Change (Vol. 2, Issue 4, pp. 243-247). https://doi.org/10.1038/nclimate1378

Milfont, T. L., \& Duckitt, J. (2010). The environmental attitudes inventory: A valid and reliable measure to assess the structure of environmental attitudes. Journal of Environmental Psychology, 30(1), 80-94. https://doi.org/10.1016/j.jenvp.2009.09.001

Munton, A. G., Wright, A. J., Mallaburn, P. S., \& Boait, P. . (2014). How heating controls affect domestic energy demand: A Rapid Evidence Assessment. January, 10-63. www.gov.uk/decc.

Olson, J. M., \& Stone, J. (2005). The Influence of Behavior on Attitudes. The Handbook of Attitudes, 223-271. https://doi.org/Mahwah, NJ

Ouellette, J. A., \& Wood, W. (1998). Habit and Intention in Everyday Life: The Multiple Processes by Which Past Behavior Predicts Future Behavior. Psychological Bulletin, 124(1), 54-74. https://doi.org/10.1037/0033-2909.124.1.54

Palmer, J., Terry, N., \& Pope, P. (2012). How much energy could be saved by making small changes to everyday household behaviours?

Pichert, D., \& Katsikopoulos, K. V. (2008). Green defaults: Information presentation and pro-environmental behaviour. Journal of Environmental Psychology, 28(1), 63-73. https://doi.org/10.1016/j.jenvp.2007.09.004

Political Trackers / Survey results / YouGov. (n.d.). Retrieved January 27, 2020, from https://yougov.co.uk/topics/political-trackers/survey-results

Redondo, I., \& Puelles, M. (2017). The connection between environmental attitudebehavior gap and other individual inconsistencies: a call for strengthening self-control. International Research in Geographical and Environmental Education, 26(2), 107120. https://doi.org/10.1080/10382046.2016.1235361

Siegel, J. T., Navarro, M. A., Tan, C. N., \& Hyde, M. K. (2014). Attitude-behavior consistency, the principle of compatibility, and organ donation: A classic innovation. Health Psychology, 33(9), 1084-1091. https://doi.org/10.1037/hea0000062

Steg, L., \& Vlek, C. (2008). Encouraging pro-environmental behaviour: An integrative review and research agenda. https://doi.org/10.1016/j.jenvp.2008.10.004

Stern, P. C. (2000a). Toward a Coherent Theory of Environmentally Significant Behavior. In Journal of Social Issues (Vol. 56, Issue 3).

Stern, P. C. (2000b). New Environmental Theories: Toward a Coherent Theory of Environmentally Significant Behavior. Journal of Social Issues, 56(3), 407-424. https://doi.org/10.1111/0022-4537.00175 
Stern, P. C., \& Dietz, T. (1994). The Value Basis of Environmental Concern. Journal of Social Issues, 50(3), 65-84. https://doi.org/10.1111/j.1540-4560.1994.tb02420.x

Thapa, B. (2010). The mediation effect of outdoor recreation participation on environmental attitude-behavior correspondence. Journal of Environmental Education, 41(3), 133-150. https://doi.org/10.1080/00958960903439989

Thøgersen, J. (1996). Recycling and morality: A critical review of the literature. In Environment and Behavior (Vol. 28, Issue 4, pp. 536-558). https://doi.org/10.1177/0013916596284006

Tillas, A. (2015). Language as grist to the mill of cognition. In Cognitive Processing (Vol. 16, Issue 3, pp. 219-243). Springer Verlag. https://doi.org/10.1007/s10339-015-06562

Tversky, A., \& Kahneman, D. (1991). Loss Aversion in Riskless Choice: A ReferenceDependent Model. The Quarterly Journal of Economics, 106(4), 1039-1061. https://doi.org/10.2307/2937956

Vesely, S., \& Klöckner, C. A. (2018). How anonymity and norms influence costly support for environmental causes. Journal of Environmental Psychology, 58, 27-30. https://doi.org/10.1016/j.jenvp.2018.07.013

Waters, L. (2019). Energy Consumption in the UK (ECUK) 1970 to 2018. https://www.gov.uk/government/collections/digest-of-uk-energy-statistics-dukes

Williams, K. M., Orpen, S., Hutchinson, L. R., Walker, L. J., \& Zumbo, B. D. (2006). Personality, Empathy, and Moral Development: Examining Ethical Reasoning in Relation to the Big Five and the Dark Triad.

Zhuang, X., \& Wu, C. (2019). The effect of interactive feedback on attitude and behavior change in setting air conditioners in the workplace. Energy and Buildings, 183, 739748. https://doi.org/10.1016/j.enbuild.2018.11.040 


\section{Appendices}

\section{Appendix 1 (email copy)}

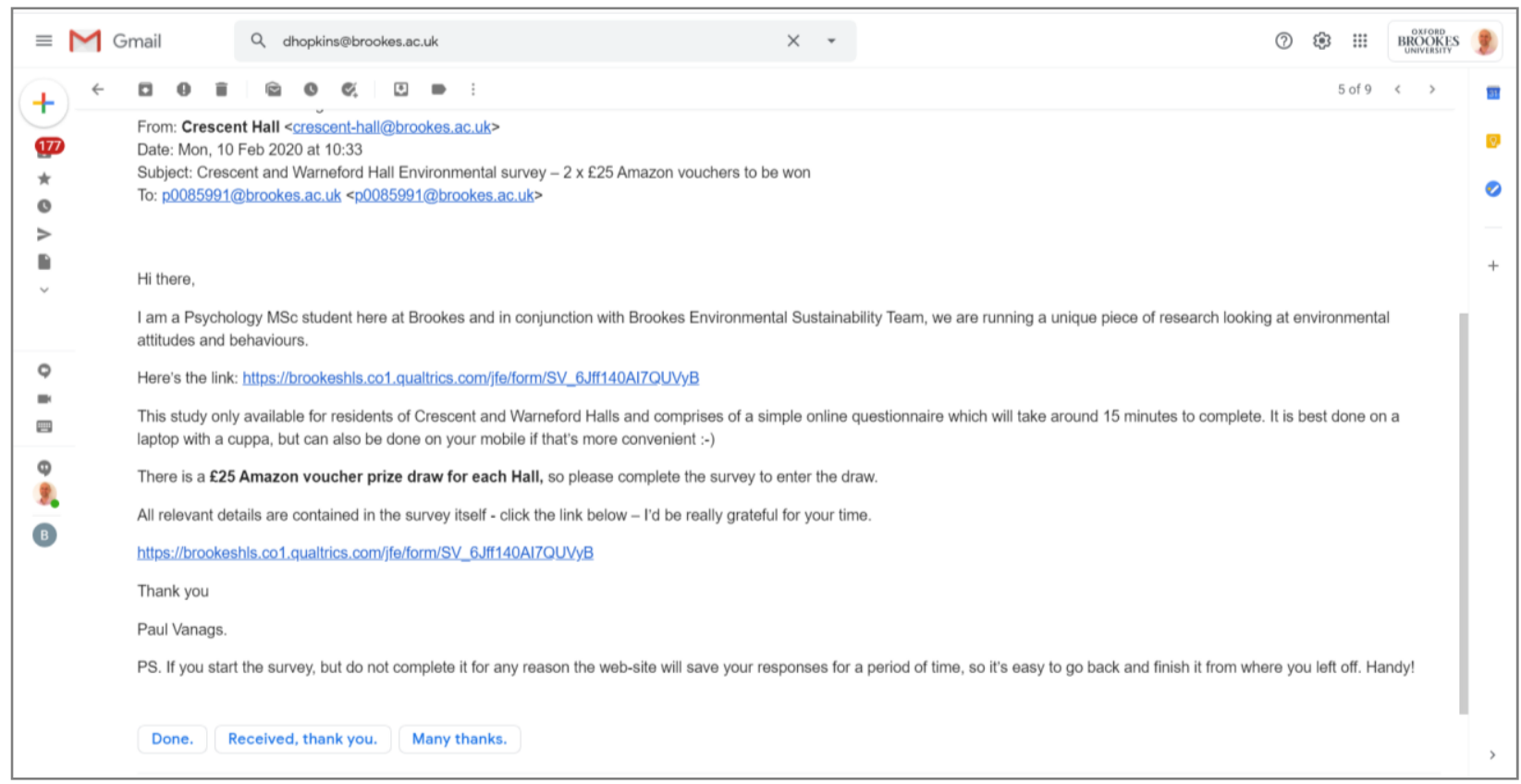




\section{Appendix 2 (supplementary tables)}

MULTI-LEVEL MODELS USING THERMOSTAT DATA INCLUDING DEFAULT SETTINGS

TABLE 13: MIXED MODEL REGRESSION RESULTS WITH DEPENDENT VARIABLE AS MEAN SETPOINT $\left({ }^{\circ} \mathrm{C}\right)$ INCLUDING DEFAULT SETTINGS

\begin{tabular}{|c|c|c|c|c|c|c|c|c|c|c|c|c|c|c|c|}
\hline \multirow[b]{2}{*}{ Predictors } & \multicolumn{3}{|c|}{ Model 1} & \multicolumn{3}{|c|}{ Model 2} & \multicolumn{3}{|c|}{ Model 3} & \multicolumn{3}{|c|}{ Model 4} & \multicolumn{3}{|c|}{ Model 5} \\
\hline & Estimates & $\mathrm{Cl}$ & $p$ & Estimates & $\mathrm{Cl}$ & $p$ & Estimates & $\mathrm{Cl}$ & $p$ & Estimates & $\mathrm{Cl}$ & $p$ & Estimates & $\mathrm{Cl}$ & $p$ \\
\hline (Intercept) & 0.09 & $\begin{array}{c}0.02- \\
0.17\end{array}$ & 0.018 & 0.10 & $\begin{array}{c}0.03- \\
0.18\end{array}$ & 0.008 & 0.10 & $\begin{array}{c}0.02- \\
0.18\end{array}$ & 0.010 & 0.12 & $\begin{array}{c}0.02- \\
0.22\end{array}$ & 0.021 & 0.10 & $\begin{array}{c}-0.01- \\
0.20\end{array}$ & 0.066 \\
\hline Day & -0.00 & $\begin{array}{c}-0.00- \\
-0.00\end{array}$ & $<0.001$ & -0.00 & $\begin{array}{c}-0.00- \\
-0.00\end{array}$ & $<0.001$ & -0.00 & $\begin{array}{c}-0.00- \\
-0.00\end{array}$ & $<0.001$ & -0.00 & $\begin{array}{c}-0.00- \\
-0.00\end{array}$ & $<0.001$ & -0.00 & $\begin{array}{l}-0.00- \\
-0.00\end{array}$ & $<0.001$ \\
\hline External temp & & & & -0.05 & $\begin{array}{c}-0.05- \\
-0.04\end{array}$ & $<0.001$ & -0.05 & $\begin{array}{c}-0.05- \\
-0.04\end{array}$ & $<0.001$ & -0.05 & $\begin{array}{c}-0.05- \\
-0.04\end{array}$ & $<0.001$ & -0.05 & $\begin{array}{c}-0.05- \\
-0.04\end{array}$ & $<0.001$ \\
\hline Manipulation & & & & & & & -0.02 & $\begin{array}{c}-0.02- \\
-0.01\end{array}$ & $<0.001$ & -0.02 & $\begin{array}{c}-0.02- \\
-0.01\end{array}$ & $<0.001$ & 0.04 & $\begin{array}{c}0.03- \\
0.04\end{array}$ & $<0.001$ \\
\hline Condition [Generic] & & & & & & & & & & -0.05 & $\begin{array}{c}-0.20- \\
0.11\end{array}$ & 0.544 & 0.01 & $\begin{array}{c}-0.14- \\
0.16\end{array}$ & 0.918 \\
\hline $\begin{array}{l}\text { Manipulation * } \\
\text { Condition [Generic] }\end{array}$ & & & & & & & & & & & & & -0.11 & $\begin{array}{c}-0.12- \\
-0.11\end{array}$ & $<0.001$ \\
\hline \multicolumn{16}{|l|}{ Random Effects } \\
\hline $\mathrm{N}$ & \multicolumn{2}{|c|}{551 site_room } & \multicolumn{3}{|c|}{551 site_room } & \multicolumn{3}{|c|}{551 site_room } & \multicolumn{3}{|c|}{551 site_room } & \multicolumn{3}{|c|}{551 site_room } & \\
\hline Observations & \multicolumn{2}{|l|}{380675} & \multicolumn{3}{|c|}{380675} & \multicolumn{3}{|c|}{380675} & \multicolumn{3}{|c|}{380675} & \multicolumn{3}{|c|}{380675} & \\
\hline $\begin{array}{l}\text { Marginal } R^{2} / \\
\text { Conditional } R^{2}\end{array}$ & \multicolumn{2}{|c|}{$0.000 / 0.689$} & \multicolumn{3}{|c|}{0.002 / 0.691} & \multicolumn{3}{|c|}{0.002 / 0.691} & \multicolumn{3}{|c|}{0.002 / 0.691} & \multicolumn{3}{|c|}{$0.003 / 0.692$} & \\
\hline
\end{tabular}


TABLE 14: MIXED MODEL RESULTS FOR SURVEY PARTICIPANTS (MEAN SETPOINT IN ${ }^{\circ} \mathrm{C}$ INCLUSIVE OF DEFAULTS)

\begin{tabular}{|c|c|c|c|c|c|c|c|c|c|c|c|c|c|c|c|}
\hline \multirow[b]{2}{*}{ Predictors } & \multicolumn{3}{|c|}{ Model 1} & \multicolumn{3}{|c|}{ Model 2} & \multicolumn{3}{|c|}{ Model 3} & \multicolumn{3}{|c|}{ Model 4} & \multicolumn{3}{|c|}{ Model 5} \\
\hline & Estimates & $\mathrm{Cl}$ & $p$ & Estimates & $\mathrm{Cl}$ & $p$ & Estimates & $\mathrm{Cl}$ & $p$ & Estimates & $\mathrm{Cl}$ & $p$ & Estimates & $\mathrm{Cl}$ & $p$ \\
\hline (Intercept) & -0.08 & $\begin{array}{c}-0.30- \\
0.14\end{array}$ & 0.456 & -0.08 & $\begin{array}{c}-0.30- \\
0.14\end{array}$ & 0.498 & -0.05 & $\begin{array}{c}-0.28- \\
0.17\end{array}$ & 0.627 & -0.08 & $\begin{array}{c}-0.39- \\
0.23\end{array}$ & 0.607 & -0.13 & $\begin{array}{c}-0.44- \\
0.18\end{array}$ & 0.421 \\
\hline Day & -0.00 & $\begin{array}{c}-0.01- \\
0.00\end{array}$ & 0.151 & -0.00 & $\begin{array}{c}-0.01- \\
0.00\end{array}$ & 0.081 & -0.01 & $\begin{array}{c}-0.01- \\
-0.00\end{array}$ & 0.029 & -0.01 & $\begin{array}{c}-0.01- \\
-0.00\end{array}$ & 0.029 & -0.01 & $\begin{array}{l}-0.01- \\
-0.00\end{array}$ & 0.029 \\
\hline External temp & & & & -0.03 & $\begin{array}{c}-0.06- \\
-0.00\end{array}$ & 0.022 & -0.03 & $\begin{array}{c}-0.06- \\
-0.01\end{array}$ & 0.014 & -0.03 & $\begin{array}{c}-0.06- \\
-0.01\end{array}$ & 0.014 & -0.03 & $\begin{array}{c}-0.06- \\
-0.01\end{array}$ & 0.013 \\
\hline Manipulation & & & & & & & 0.08 & $\begin{array}{c}-0.02- \\
0.19\end{array}$ & 0.130 & 0.08 & $\begin{array}{c}-0.02- \\
0.19\end{array}$ & 0.130 & 0.18 & $\begin{array}{c}0.06- \\
0.30\end{array}$ & 0.004 \\
\hline Condition [Generic] & & & & & & & & & & 0.05 & $\begin{array}{c}-0.38- \\
0.48\end{array}$ & 0.811 & 0.15 & $\begin{array}{c}-0.29- \\
0.58\end{array}$ & 0.512 \\
\hline $\begin{array}{l}\text { Manipulation * } \\
\text { Condition [Generic] }\end{array}$ & & & & & & & & & & & & & -0.19 & $\begin{array}{l}-0.30- \\
-0.08\end{array}$ & $<0.001$ \\
\hline \multicolumn{16}{|l|}{ Random Effects } \\
\hline $\mathrm{N}$ & \multicolumn{2}{|c|}{86 Responseld } & & \multicolumn{2}{|c|}{86 Responseld } & \multicolumn{3}{|c|}{86 Responseld } & \multicolumn{3}{|c|}{86 Responseld } & \multicolumn{3}{|c|}{86 Responseld } & \\
\hline Observations & \multicolumn{2}{|l|}{2493} & & \multicolumn{2}{|l|}{2493} & \multicolumn{3}{|c|}{2493} & \multicolumn{3}{|c|}{2493} & \multicolumn{3}{|c|}{2493} & \\
\hline $\begin{array}{l}\text { Marginal } R^{2} / \\
\text { Conditional } R^{2}\end{array}$ & \multicolumn{2}{|c|}{$0.000 / 0.682$} & & \multicolumn{2}{|c|}{$0.001 / 0.682$} & \multicolumn{3}{|c|}{$0.001 / 0.683$} & \multicolumn{3}{|c|}{0.002 / 0.685} & \multicolumn{3}{|c|}{$0.003 / 0.687$} & \\
\hline
\end{tabular}




\section{Appendix 3 (impact calculation)}

Calculating potential impact of moralising thermostat usage across the UK

Total domestic energy used for space heating in UK (DUKES End-use table U3) $=27,144$ ktoe (thousand tonnes of oil equivalent)

\begin{tabular}{|l|l|l|l|l|l|}
\hline & $\begin{array}{l}\text { Energy used in } \\
\text { domestic } \\
\text { heating (ktoe) }\end{array}$ & $\begin{array}{l}\text { Conversion factor to } \\
\mathrm{kWh}=1.163 \times 10^{7}\end{array}$ & $\begin{array}{l}\text { Equivalent } \\
\text { emissions }\left(\mathrm{kgCO}_{2} \mathrm{e}\right)\end{array}$ & $\begin{array}{l}\text { Estimated cost } \\
\text { (pence per } \mathrm{kWh})\end{array}$ \\
\hline Solid Fuel & 504 & $5.862 \times 10^{9}$ & $0.076 \times 10^{9}$ & - & - \\
\hline Gas & 20,570 & $239.2 \times 10^{9}$ & $440.0 \times 10^{9}$ & 4.3 & 18.92 \\
\hline Electricity & 1,564 & $18.19 \times 10^{9}$ & $7.494 \times 10^{9}$ & 17.6 & 1.31 \\
\hline Oil & 2,005 & $23.32 \times 10^{9}$ & $6.250 \times 10^{9}$ & 5.6 & -35 \\
\hline Bio-energy \& waste & 2,240 & $26.05 \times 10^{9}$ & - & - & - \\
\hline TOTAL & & & $453.8 \times 10^{9}$ & & 20.58 \\
\hline
\end{tabular}

Notes: $\mathrm{CO}_{2}$ conversions from https://www.carbontrust.com/resources/conversion-factors-energy-and-carbon-conversion-guide; solid fuels may be different materials typically wood or coal which have different emissions per kWh. For the purposes of calculation the lower value is used. No $\mathrm{CO}_{2}$ conversion value for bio-energy/waste was available and so this was excluded from the calculation. Energy prices per $\mathrm{kWh}$ from

https://www.confusedaboutenergy.co.uk/index.php/domestic-fuels/fuel-prices. 


\title{
Appendix 4 (questionnaire)
}

Full copy of questionnaire

\section{Values and Environmental Behaviours}

\author{
Q1 Faculty of Health and Life Sciences
}

Department of Psychology, Health and Professional Development

Headington Campus, Gipsy Lane, Oxford Brookes University.

Researcher: Paul Vanags, post-graduate, Email: 19010048@brookes.ac.uk

Supervisor: Dr Adam Baimel, Email: abaimel@brookes.ac.uk, Tel: 01865483741

VALUES \& ENVIRONMENTAL BEHAVIOURS STUDY

You are being invited to take part in a research study. Before you decide whether or not to take part, it is important for you to understand why the research is being done and what it will involve. Please take time to read the following information carefully.

What is the purpose of the study? Mitigating human environmental impact to create a sustainable future is one of the biggest issues facing humanity. Understanding the psychology of this is a key part of many potential solutions to these problems, like reducing consumption, household waste management or personal transport choices. This study examines values, attitudes and behaviours. The study's main aim is to test what drives attitudes to pro-environmental behaviour, and how people view this.

Why have I been invited to participate? You have been asked to take part because we want to explore the link between values, attitudes and behaviours in Brookes students residing in Warneford Hall and Crescent Hall residential blocks. We will be recruiting up to 120 participants in this study.

\section{Do I have to take part?}

It is up to you to decide whether or not to take part. If you do decide to take part you are still free to withdraw unprocessed data at any time by closing the browser before pressing the 'submit' button.

\section{What are the risks and benefits of taking part?}

There is a risk that any students suffering or already pre-disposed to climate change anxiety may be negatively affected by the study.

Further resources which may help can be found here; https://www.nhs.uk/conditions/generalised-anxiety-disorder/, https://www.bbc.co.uk/bbcthree/article/b2e7ee32-ad28-4ec4-89aa-a8b8c98f95a5

The study is specifically relevant to residents of Crescent and Warneford Halls and students may find participating and seeing the results an interesting experience.

Participants will be automatically entered into a prize draw for a £25 Amazon voucher, with one available for each of Warneford and Crescent Halls. The draw will be made on the basis of room numbers supplied and winners will be notified by email.

What will happen to me if I take part? If you are happy to take part in the study, please sign the consent form as part of the online survey. This study consists of an online questionnaire, lasting approximately 15 minutes. This information will then be analysed alongside data collected from individual room thermostat controls, regarding temperature and usage.All participants will be entered into a prize draw for one of two £25 Amazon voucher (one for each Hall). Will what I say in this study be kept confidential? Yes. Individual room numbers will be used to identify rooms for the analysis, but no emails 
or names will be available to the research team. After the analysis is complete the room numbers will be anonymised when the data is stored, so no personally identifiable information will be retained. No IP addresses will be stored. All data is held on password protected files only available to the research team.

\section{What should I do if I want to take part?}

If you would like to take part, please read and agree to the consent statements at the bottom of this page before proceeding.

\section{What will happen to the results of the research study?}

The data from this study will be used in a Masters of Science in Psychology research dissertation. We hope to publish the results of this study in a scientific journal. We may also present the results at a scientific conference or a seminar in a university. If you agree to participate in this study, the research may be stored by the University, to facilitate its use in future research. We would be happy to discuss the results of the study with you and to send you a copy of the published results once it is completed. It will not be possible to identify you in any report or publication.

Who has reviewed the study? The research has been approved by the Psychology Research Ethics Committee, Oxford Brookes University. If you have any concerns about the way in which the study has been conducted, please contact the Psychology Research Ethics Officer on edavies@brookes.ac.uk.

\section{Contact for Further Information}

Please contact the lead researcher or our supervisor if you would like any further information about this study, or would like to receive a copy of the final research. Prize winners will be notified by 30th April 2020.

Researcher: Paul Vanags, post-graduate, Email: 19010048@brookes.ac.uk Supervisor: Dr Adam Baimel, Email: abaimel@brookes.ac.uk, Tel: 01865483741 Thank you for taking time to read the information sheet.

Date 23rd January 2020 
Q2 For the purposes of carrying out this Survey, the University uses the survey tools provided by Qualtrics with whom the University's Faculty of Health and Life Sciences holds an agreement. There is always a certain element of risk of data loss when data is collected and processed in an internet environment. This risk cannot be eliminated entirely and participants consenting to take part in the survey need to be aware of this risk. However, personal data will be minimised to the extent possible for the survey and the University believes that Qualtrics offers sufficient guarantees to keep the data secure while it is being processed. These security obligations are set out in the agreement between Qualtrics and the University.

Further information about Qualtrics can be found on the following web site: http://qualtrics.com/

consent to participate in this survey

Q3 Please select your Hall

Warneford Hall

Crescent Hall

Q4 Enter your Crescent Hall room number here e.g. C2B

(this is required for the analysis as well as to enter the £25 Amazon voucher prize draw)

\section{End of Block: Participant Information}


Q5 Question 1/7: Listed below are statements about the relationship between humans and the environment. To what extent do you agree or disagree with the following statements?

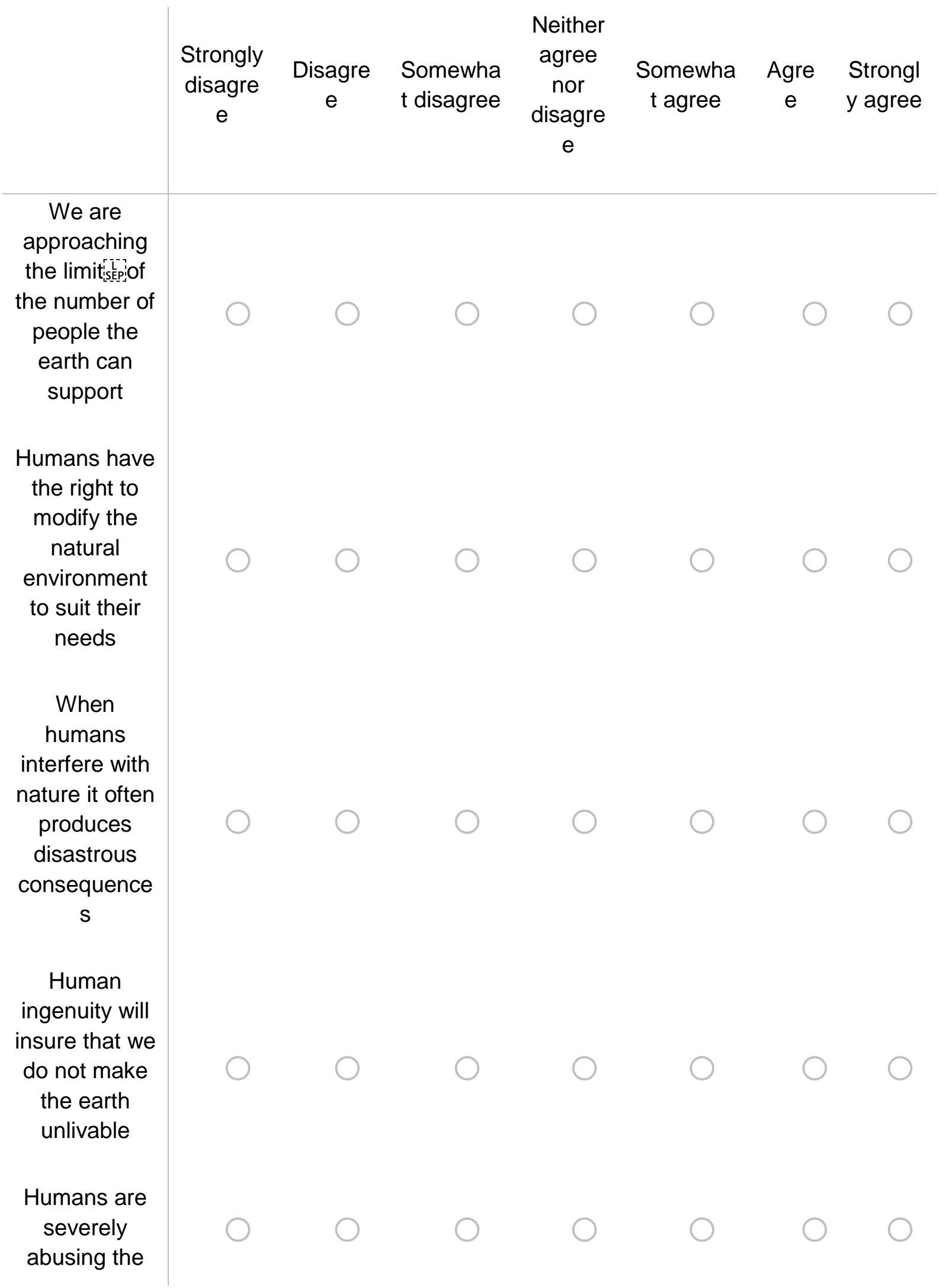


environment

The earth has plenty of natural resources if we just learn how to develop them

Plants and animals have as much right as humans to exist

The balance of nature is strong enough to cope with the impacts of modern industrial nations

Despite our special abilities humans are still subject to the laws of nature

The so-called "ecological crisis" facing humankind has been greatly exaggerated

The earth is like a spaceship 


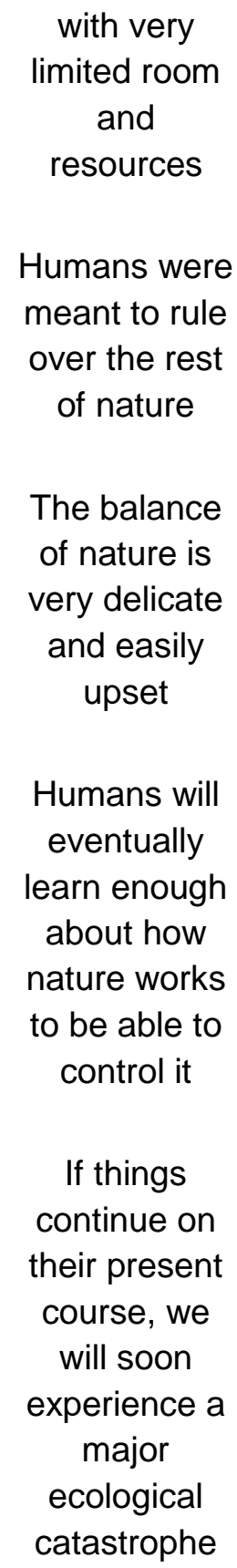

\section{End of Block: Section 2}

\section{Start of Block: Section 3}

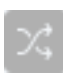

Q6 15\% complete!

Question 2/7: Listed below are further statements about the relationship between humans 
and the environment. To what extent do you agree or disagree with them?

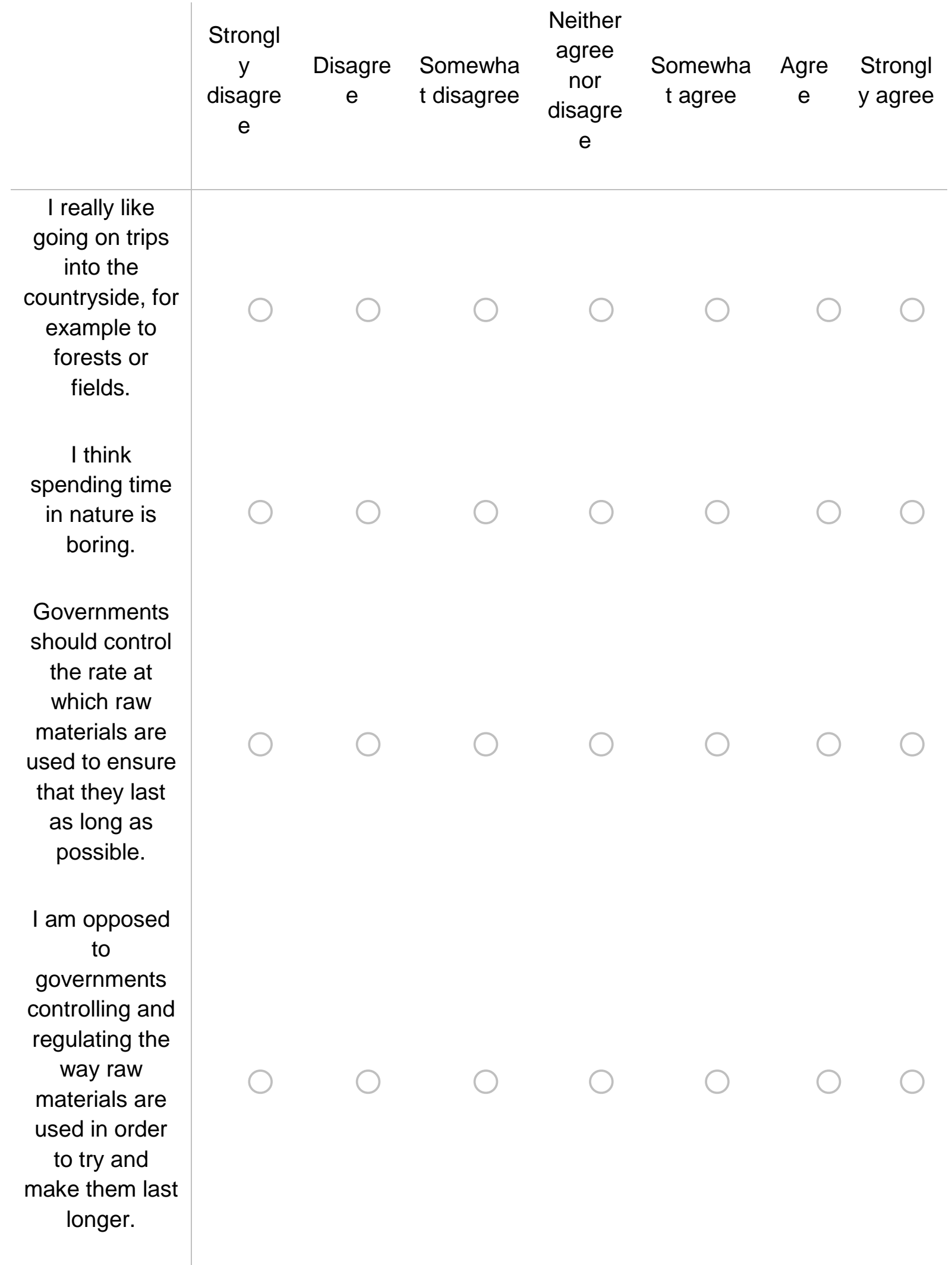


I would like to

join and

actively

participate in

an

environmentali

st group

I would NOT

get involved in

an

environmentali

st organization.

One of the

most important

reasons to

keep lakes and

rivers clean is so that people

have a place to enjoy water sports

We need to keep rivers and lakes clean in order to protect the environment, and NOT as places for people to enjoy water sports.

Modern science will

NOT be able to solve our environmental problems

Modern science will solve our 


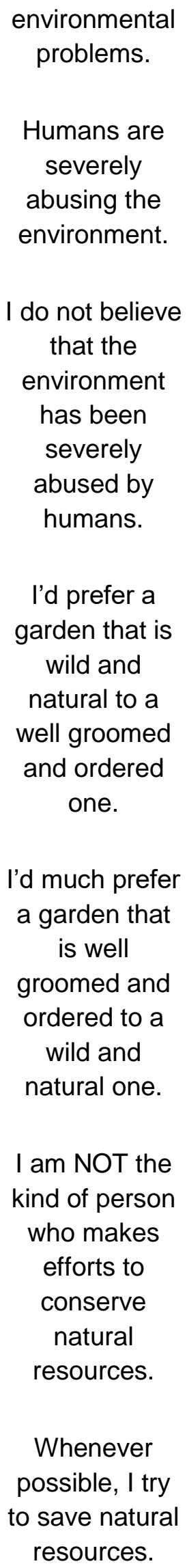

I'd much prefer a garden that is well groomed and ordered to a wild and natural one.

I am NOT the kind of person who makes efforts to conserve natural resources.

Whenever possible, I try to save natural resources. 


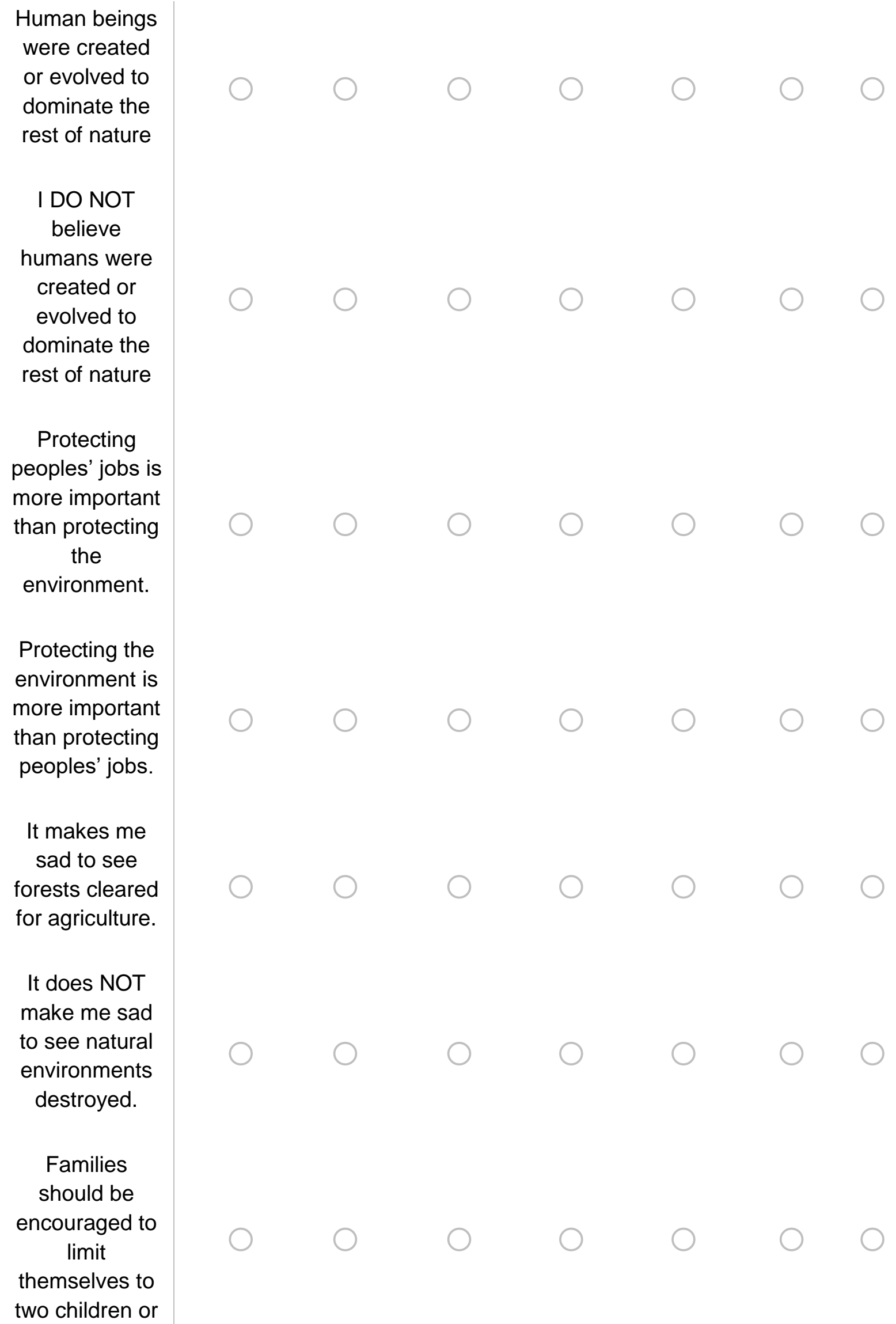


less.

A married

couple should

have as many

children as

they wish, as

long as they

can adequately

provide for

them.

End of Block: Section 3

Start of Block: Block 7 


\section{Q8}

Brilliant.. 40\% complete..

Question 3/7: To what extent do you agree or disagree with the following statements regarding the thermostatic temperature control in your room?

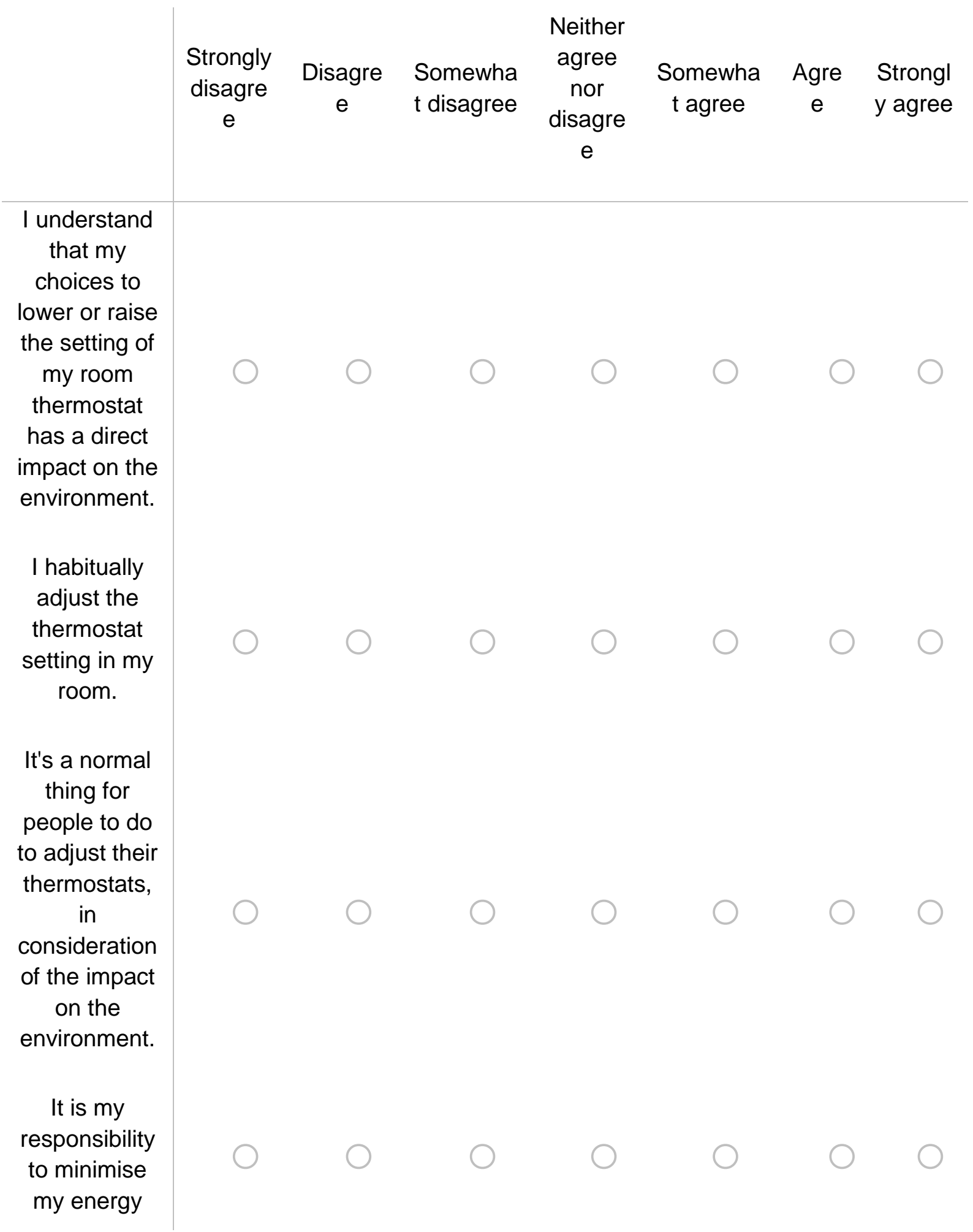




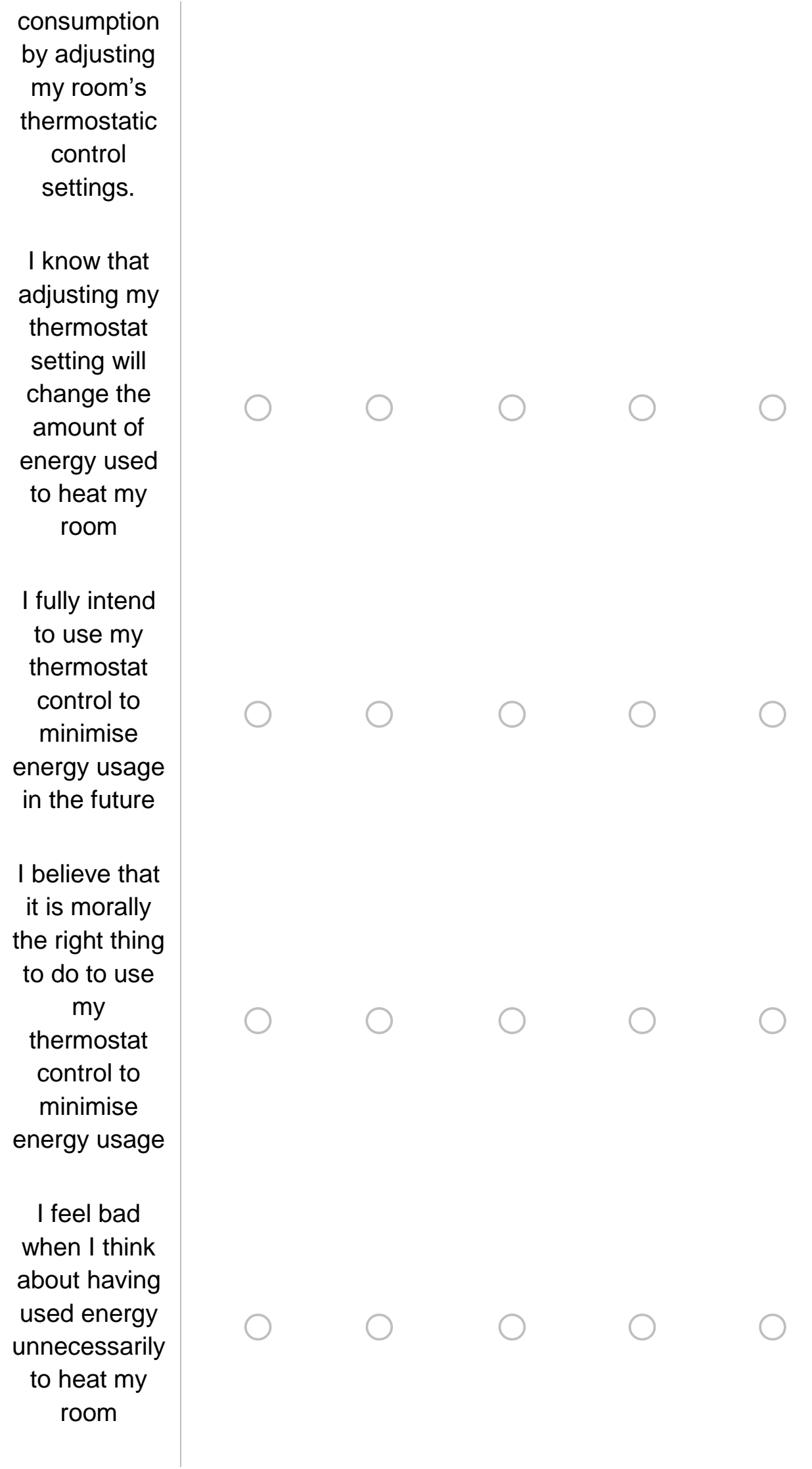


It would be

wrong to use

too much

energy to

heat my room

due to the

negative

consequence

$s$ on the

environment.

End of Block: Block 7

Start of Block: Block 6

$y_{4}$ 
Q7 Great! You're over 50\%..

Question 4/7: How likely are you to engage in the following activities in the next 12 months? If it's not possible for you to perform an activity, please choose 'not applicable'.

\begin{tabular}{|c|c|c|c|c|c|c|}
\hline $\begin{array}{c}1=\text { Not } \\
\text { at all } \\
\text { likely }\end{array}$ & 2 & 3 & $\begin{array}{c}4= \\
\text { Neither } \\
\text { likely nor }\end{array}$ & 5 & 6 & $\begin{array}{c}7 \text { = Very } \\
\text { likely }\end{array}$ \\
\hline
\end{tabular}

\section{Sign a petition}

in support of

protecting the

environment

Join or renew

membership of

an

environmental

group

Join public

demonstrations

or protests

supporting

environmental

protection

Write a letter or call your member of parliament or another government official to support environmental protection

Give money to an environmental group 


\begin{tabular}{|c|}
\hline $\begin{array}{c}\text { Read a } \\
\text { newsletter, } \\
\text { magazine or } \\
\text { other } \\
\text { publication } \\
\text { written by an } \\
\text { environmental } \\
\text { group }\end{array}$ \\
\hline $\begin{array}{l}\text { If a local or } \\
\text { national } \\
\text { election was } \\
\text { called, vote for } \\
\text { a candidate in } \\
\text { part because } \\
\text { he or she was } \\
\text { in favour of } \\
\text { strong } \\
\text { environmental } \\
\text { protection }\end{array}$ \\
\hline $\begin{array}{l}\text { Write to a } \\
\text { newspaper in } \\
\text { support of } \\
\text { protecting the } \\
\text { environment }\end{array}$ \\
\hline $\begin{array}{l}\text { Boycott } \\
\text { companies that } \\
\text { are not } \\
\text { environmentally } \\
\text { friendly }\end{array}$ \\
\hline $\begin{array}{l}\text { Volunteer to } \\
\text { help an } \\
\text { environmental } \\
\text { group or event }\end{array}$ \\
\hline $\begin{array}{l}\text { Post pro- } \\
\text { environmental } \\
\text { messages or } \\
\text { links on social } \\
\text { media (for } \\
\text { example, } \\
\text { Facebook, }\end{array}$ \\
\hline
\end{tabular}




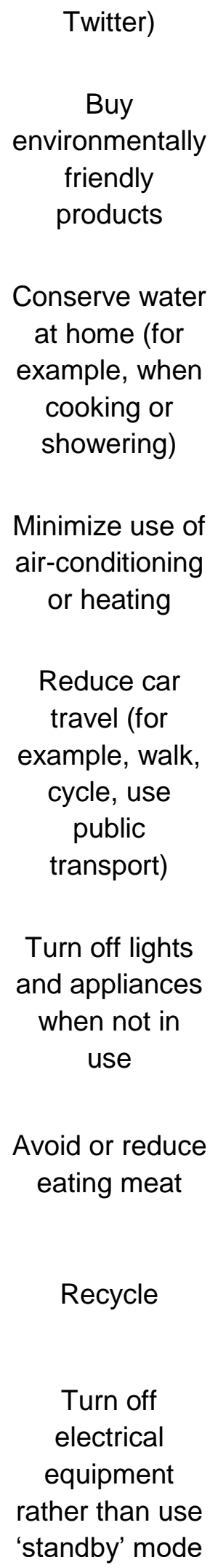




\section{Eat food which}

is locally-grown or in season

Use carsharing or carpooling schemes

Buy products with less packaging 
Q9 Thanks so much, you've completed $75 \%$ of the survey..

QUESTION 5/7: Please indicate the extent to which you agree or disagree with the following: "Protecting the environment and its natural resources is important because..."

\begin{tabular}{|c|c|c|c|c|c|c|c|}
\hline & $\begin{array}{l}\text { Strongly } \\
\text { disagree }\end{array}$ & Disagree & $\begin{array}{l}\text { Somewhat } \\
\text { disagree }\end{array}$ & $\begin{array}{c}\text { Neither } \\
\text { agree } \\
\text { nor } \\
\text { disagree }\end{array}$ & $\begin{array}{l}\text { Somewhat } \\
\text { agree }\end{array}$ & Agree & $\begin{array}{c}\text { Strongly } \\
\text { agree }\end{array}$ \\
\hline $\begin{array}{c}\text { It } \\
\text { safeguards } \\
\text { my family's } \\
\text { future }\end{array}$ & O & & $C$ & & & & O \\
\hline $\begin{array}{l}\text { It is the } \\
\text { duty of } \\
\text { every } \\
\text { student }\end{array}$ & & & C & & & & ( \\
\hline $\begin{array}{l}\text { It repays } \\
\text { the natural } \\
\text { world for } \\
\text { what it has } \\
\text { provided } \\
\text { for us }\end{array}$ & C & C & $\bigcirc$ & $\mathrm{C}$ & & & 0 \\
\hline $\begin{array}{l}\text { It exhibits } \\
\text { courage to } \\
\text { stand up } \\
\text { for what is } \\
\text { right }\end{array}$ & & & & & & & \\
\hline $\begin{array}{l}\text { It shows } \\
\text { respect for } \\
\text { nature }\end{array}$ & ( & & $\bigcirc$ & & & & \\
\hline $\begin{array}{l}\text { Nobody } \\
\text { should } \\
\text { take more } \\
\text { than their } \\
\text { fair share } \\
\text { of the } \\
\text { world's }\end{array}$ & ) & 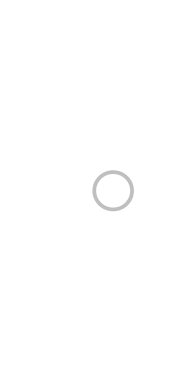 & $b$ & $\Omega$ & 0 & & 2 \\
\hline
\end{tabular}


natural

resources

It

preserves

our

heritage,

which is a

valuable

End of Block: Block 8

Start of Block: Block 9 
Q10 85\% done.. last page..

Question 6/7: Please indicate the extent to which you agree or disagree with the following: "Allowing the degradation of the environment and its natural resources is unacceptable because..."

\begin{tabular}{|c|c|c|c|c|c|c|c|}
\hline & $\begin{array}{c}\text { Strongly } \\
\text { disagre } \\
\text { e }\end{array}$ & $\begin{array}{c}\text { Disagre } \\
\mathrm{e}\end{array}$ & $\begin{array}{l}\text { Somewha } \\
\text { t disagree }\end{array}$ & $\begin{array}{l}\text { Neither } \\
\text { agree } \\
\text { nor } \\
\text { disagre } \\
\mathrm{e}\end{array}$ & $\begin{array}{c}\text { Somewha } \\
\text { t agree }\end{array}$ & $\begin{array}{c}\text { Agre } \\
\mathrm{e}\end{array}$ & $\begin{array}{l}\text { Strongl } \\
\text { y agree }\end{array}$ \\
\hline $\begin{array}{l}\text { It is morally } \\
\text { wrong }\end{array}$ & & 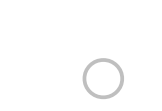 & & C & & & \\
\hline $\begin{array}{l}\text { It is } \\
\text { deserving of } \\
\text { punishment }\end{array}$ & & & & & & & \\
\hline It is unfair & 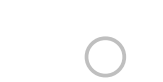 & 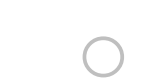 & & & & & \\
\hline $\begin{array}{c}\text { It is } \\
\text { disgusting }\end{array}$ & & & & & & & \\
\hline It is disloyal & & & & & & & \\
\hline $\begin{array}{c}\text { It is } \\
\text { disrespectfu }\end{array}$ & & & & & & & \\
\hline It is harmful & 0 & 0 & 0 & 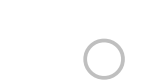 & & & \\
\hline
\end{tabular}


Q11 Question 7/7: Using the scale provided, please indicate how much each of the following statements reflects how you typically are.

\begin{tabular}{|c|c|c|c|c|c|}
\hline & $1=$ Not at all & 2 & 3 & 4 & $\begin{array}{c}5=\text { Very } \\
\text { much }\end{array}$ \\
\hline $\begin{array}{l}\text { I am good at } \\
\text { resisting } \\
\text { temptation }\end{array}$ & & & & & \\
\hline $\begin{array}{l}\text { I have a hard } \\
\text { time breaking } \\
\text { habits }\end{array}$ & & & & & \\
\hline I am lazy & 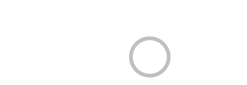 & & & & \\
\hline $\begin{array}{l}\text { I say } \\
\text { inappropriate } \\
\text { things }\end{array}$ & & & & & \\
\hline $\begin{array}{l}\text { I do certain } \\
\text { things that } \\
\text { are bad for } \\
\text { me, if they } \\
\text { are fun }\end{array}$ & & & & & \\
\hline $\begin{array}{l}\text { I refuse } \\
\text { things that } \\
\text { are bad for } \\
\text { me }\end{array}$ & & & & & \\
\hline $\begin{array}{l}\text { I wish I had } \\
\text { more self- } \\
\text { discipline }\end{array}$ & & & & & \\
\hline $\begin{array}{l}\text { People would } \\
\text { say that I } \\
\text { have iron } \\
\text { self-discipline }\end{array}$ & 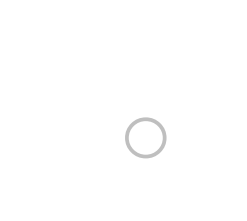 & & & & \\
\hline $\begin{array}{c}\text { Pleasure and } \\
\text { fun } \\
\text { sometimes }\end{array}$ & 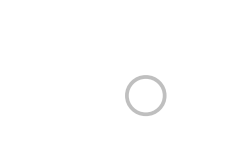 & & & & \\
\hline
\end{tabular}




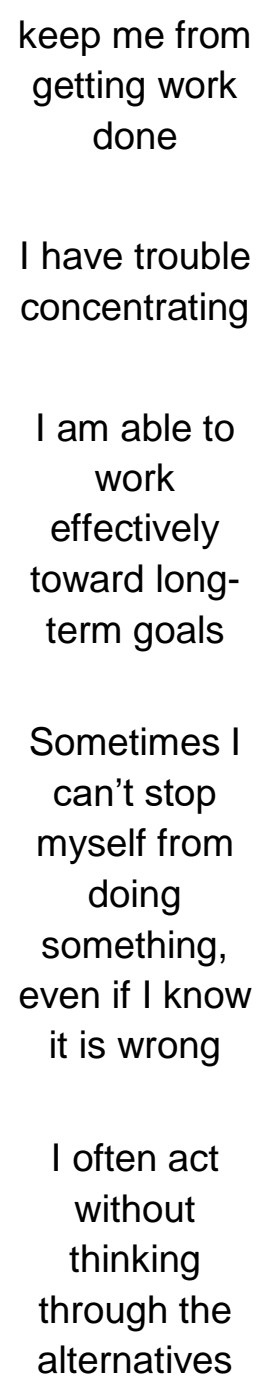


Q12 Thank you for the time you have spent responding to our questions. In order to help us describe our participants, please answer the following.

Q13 What gender are you?
Woman
Man
Non-binary
Different Identity

Q34 How old are you (in years)?

$\nabla 18 \ldots 70$ 
Q15 What is your ethnic group?

White

Mixed / Multiple ethnic groups

Asian / Asian British

Black / African / Caribbean / Black British

Other ethnic group

Q35 What is your political orientation?

\begin{tabular}{|c|c|c|c|c|c|c|c|}
\hline & $\begin{array}{c}1=\text { Very } \\
\text { conservative }\end{array}$ & 2 & 3 & 4 & 5 & 6 & $\begin{array}{c}7=\text { Very } \\
\text { liberal }\end{array}$ \\
\hline $\begin{array}{l}\text { Political } \\
\text { orientation }\end{array}$ & 0 & & & & & & 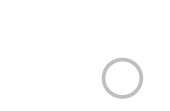 \\
\hline
\end{tabular}

Q17 Were you born in the UK?
Yes
No 
Q18 In which country were you born?

Q19 In which country were you raised?

Q20 How long have you lived in the UK? 